\title{
Simulation and Analyses of Stage Separation Two-Stage Reusable Launch Vehicles
}

\author{
Bandu N. Pamadi, ${ }^{*}$ Thomas A. Neirynck, ${ }^{\dagger}$ Nathaniel J. Hotchko, ${ }^{\ddagger}$ \\ Paul V. Tartabini, ${ }^{\S}$ and William I. Scallion, ${ }^{* *}$ Kelly J. Murphy, ${ }^{\dagger \dagger}$ and Peter F. Covell ${ }^{\sharp}$ \\ NASA Langley Research Center, Hampton, VA, 23681, USA
}

\begin{abstract}
NASA has initiated the development of methodologies, techniques and tools needed for analysis and simulation of stage separation of next generation reusable launch vehicles. As a part of this activity, ConSep simulation tool is being developed which is a MATLAB-based front-and-back-end to the commercially available ADAMS ${ }^{\square}$ solver, an industry standard package for solving multi-body dynamic problems. This paper discusses the application of ConSep to the simulation and analysis of staging maneuvers of two-stage-to-orbit (TSTO) Bimese reusable launch vehicles, one staging at Mach 3 and the other at Mach 6. The proximity and isolated aerodynamic database were assembled using the data from wind tunnel tests conducted at NASA Langley Research Center. The effects of parametric variations in mass, inertia, flight path angle, altitude from their nominal values at staging were evaluated. Monte Carlo runs were performed for Mach 3 staging to evaluate the sensitivity to uncertainties in aerodynamic coefficients.
\end{abstract}

\section{Nomenclature}

$\begin{array}{ll}\square & =\text { angle of attack, deg } \\ \square \square & =\text { relative difference in angle of attack, deg } \\ C_{A} & =\text { axial force coefficient } \\ C_{N} C_{N} & =\text { normal force coefficient } \\ C_{m} C_{m} & =\text { pitching moment coefficient } \\ \square & =\text { elevon deflection, deg } \\ \square & =\text { flight path angle, deg } \\ \mathrm{h} & =\text { altitude, } \mathrm{ft} \\ I_{x x}, I_{y y}, I_{z z} & =\text { moment of inertia about body } \mathrm{x}, \mathrm{y}, \mathrm{z} \text { axis } \\ k_{1} & =\text { interpolation constant } \\ k_{a}, k_{q} & =\text { angle of attack and pitch rate feedback gains } \\ l_{r e f} & =\text { reference length, } \mathrm{ft} \\ \mathrm{M} & =\text { Mach number } \\ \bar{q} & =\text { dynamic pressure, lbs/sft } \\ \square & =\text { density, slugs/ft } \\ S_{r e f} & =\text { reference area, } \mathrm{ft}^{2} \\ \mathrm{~V} & =\text { velocity, } \mathrm{ft} / \mathrm{s} \\ \square x, \square z & =\text { relative axial and normal distances during separation, } \mathrm{ft} \\ x_{c g} & =\text { x-location of center of gravity, } \mathrm{ft} \\ z_{c g} & =\text { z-location of center of gravity, } \mathrm{ft}\end{array}$

\footnotetext{
${ }^{*}$ Aerospace Engineer, Exploration Concept Branch, Associate Fellow AIAA.

† Graduate Student, George Washington University.

${ }^{\ddagger}$ Project Engineer, Analytical Mechanics Associates, Hampton, VA, Member AIAA.

${ }^{\S}$ Aerospace Engineer, Exploration Concepts Branch, Member AIAA.

${ }^{* *}$ Aerospace Engineer, Aerothermodynamics Branch.

${ }^{i \dagger}$ Aerospace Engineer, Aerothermodynamics Branch

Aerospace Engineer, Exploration Concepts Branch, Senior Member AIAA.
} 

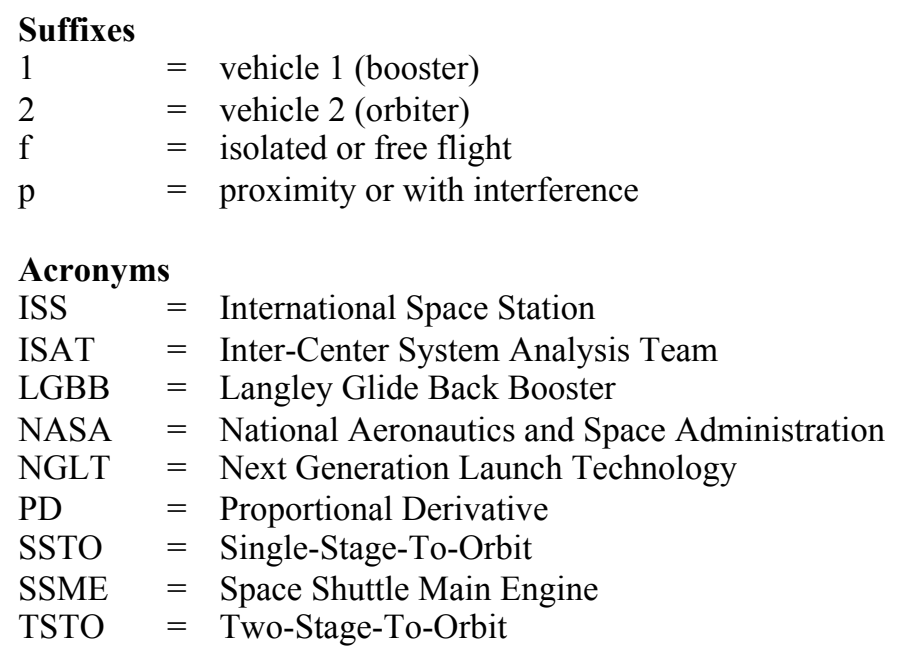

\section{Introduction}

$\mathrm{T}$ HE problem of dynamic separation of two bodies within the atmosphere is complex and challenging. One problem that has received significant attention in literature is that of store separation from the aircraft. ${ }^{1}$ The aerodynamic characteristics of the relatively small sized store are influenced by the proximity of the aircraft but those of the aircraft are virtually not affected. A similar example is the separation of the X-15 research vehicle from the B-52 carrier aircraft. ${ }^{2}$ Here, the aerodynamic characteristics of the relatively smaller X-15 vehicle are influenced by the proximity of the B-52 aircraft but not vice-versa. The other class of stage separation problem involves separation of two vehicles of comparable sizes where the aerodynamic characteristics of one vehicle are influenced by the proximity to the other vehicle. However, in some cases the integrity of only one vehicle may be of importance, such as the staging of multi-stage expendable launch vehicles. The integrity of only the upper stages is of primary concern post separation. The expended stages need only to move away safely from the upper stages before their eventual disintegration. For multi-stage reusable launch vehicles, the integrity of each stage is important post separation.

NASA studies ${ }^{3-7}$ on stage separation of multi-stage reusable launch vehicles date back to early 1960 s. These studies were conducted by Decker et al and addressed the problem of separation of generic two-stage reusable launch vehicles. Wind tunnel tests were conducted to evaluate the mutual aerodynamic interference between the two stages for supersonic/hypersonic speeds. However, the test data were limited to very few longitudinal and normal separation distances. Also, the simulation did not include the attachment between the stages and the release mechanism. Recent NASA studies by Naftel et al ${ }^{8-10}$ consider Mach 3 staging of two winged vehicles. They modeled the attachment of stages, the release mechanism in their simulations and used active control during separation but their aerodynamic data did not include the mutual interference effects. They used free-stream aerodynamic data for each vehicle.

The interest in stage-separation research has come back when it was realized during early 2000 that the technologies needed for the development of next generation reusable SSTO vehicle are not yet available and NASA's Next Generation Launch Technology (NGLT) Program identified stage separation as one of the critical technologies needed for successful development and operation of NASA's next generation multistage reusable launch vehicles. As a step towards developing this critically needed technology, NASA has initiated a comprehensive stage separation tool development activity that includes wind tunnel testing, development and validation of CFD and engineering level tools. The stage separation analysis and simulation tool called ConSep is being developed as a part of this activity. The reusable booster, a product of the NASA in-house small launcher vehicle concept study ${ }^{n}$, is used in a bimese configuration as the baseline vehicle in this tool development activity. This reusable booster concept is referred to as the Langley Glide-Back Booster ${ }^{11}$ (LGBB). Stage separation wind tunnel tests were conducted on the LGBB Bimese models at supersonic $(\mathrm{M}=2.3,3.0$ and 4.5) and hypersonic Mach number $(\mathrm{M}=6)$ to provide data for CFD code development and validation. An overview of NASA's stageseparation tool development activity is presented in Ref. 12.

The objective of this paper is to demonstrate the application of ConSep for the stage separation of two-stage-toorbit (TSTO) LGBB-Bimese reusable launch vehicles. In this study, the staging of two vehicle concepts are considered, one which stages at Mach 3 with booster glide back to launch site and the other stages at Mach 6 with a 
booster that flies back to the launch site using air breathing jet engines. The two flight profiles are illustrated in Fig. 1. The simulation and analyses performed in this study are limited to the stage separation events. The ascent and glideback/flyback trajectories are not addressed here. The initial conditions for the staging maneuvers used here are based on the available ascent trajectories of similar vehicles staging at Mach 3 and Mach 6. For each vehicle, the aerodynamic database was assembled from the wind tunnel test data generated as part of the stage separation tool development activity. These two databases include the static longitudinal aerodynamic coefficients for proximity conditions and interference-free or isolated conditions. The lateral/directional motion during stage separation is not addressed in this study.

It was found that aerodynamic separation is feasible for Mach 3 staging LGBB-Bimese vehicle. The booster and orbiter could be safely flown apart using a simple active (closed-loop feedback) control of aerodynamic surfaces (elevons). However, for Mach 6 LGBB-Bimese vehicle, aerodynamic separation was not feasible and separation motors were used to accomplish safe separation. This study also discusses the effect of variations in mass, inertia, altitude, flight path angle at staging on the vehicle motion during stage separation. To evaluate the sensitivity of the vehicle motion to uncertainties in aerodynamic coefficients, Monte Carlo studies were performed for the LGBBBimese Mach 3 stage separation. Some early results of this study were presented at the a recent AIAA conference. ${ }^{13}$

\section{Vehicle Description}

The TSTO vehicles used in this study are bimese concepts. A TSTO vehicle in which both the booster and the orbiter have the same outer-mold-lines is called a bimese vehicle. In other words, external geometry of both the booster and orbiter are identical. However, the "true" bimese vehicles are identical internally and externally to the extent that the role of the booster and orbiter can be switched. For the bimese vehicles used in this study, the outermold-lines of both the booster and orbiter are identical to that of LGBB of the small launcher ${ }^{11}$ shown in Fig. 2. However, the LGBB-Bimese vehicles do not feature canards. Furthermore, both the LGBB-Bimese booster and orbiter are approximately 4.16 times larger in size than LGBB of the small launcher. A schematic arrangement of the belly-to-belly LGBB-Bimese configuration is presented in Fig. 3.

The sizing of the two LGBB-Bimese vehicles used in this study was based on Mach 3 Glideback and Mach 5 Flyback reference configurations developed during the NASA's ISAT (Intercenter Systems Analysis Team) effort which was part of the NGLT program. The LGBB-Bimese vehicles are sized for 35,000 lb payload to the ISS (International Space Station). For the purpose of this study, the SSME (Space Shuttle Main Engine) class engines were used for each stage. The ISAT Mach 3 configuration is very close to being considered a true "bimese" in that: 1) The outer mold lines are exactly the same, and 2) the internal arrangement is as similar as is practical, particularly in regards to tanks, primary structure and engines. Only the orbiter has a reentry thermal protection system and payload provisions. The ISAT Mach 3 configuration uses fuel crossfeed from the booster to orbiter to maintain orbiter tanks full at staging. The orbiter of the ISAT Mach 5 configuration was slightly smaller than the booster and hence was not a true "bimese" configuration. The ISAT Mach 5 configuration booster uses 6 turbofan engines (20,000 $\mathrm{lb}$ thrust class) for flyback to the launch site, as the downrange was too great for glideback. These ISAT reference vehicles assume the state-of-the-art technology in the design. Application of advanced technology would reduce the vehicle size, but this was not attempted in the present study.

The Mach 3 LGBB-Bimese configuration of the present study is very similar in mass to the ISAT Mach 3 configuration. However, the Mach 6 LGBB-Bimese configuration is a scaled up version of the Mach 5 ISAT configuration, and the orbiter grown even further to match the size of the booster. In order for this Mach 6 LGBBBimese configuration to meet the mission requirements, the orbiter had to use some of its internal fuel prior to staging. Hence at separation, the orbiter's tanks are assumed to be less than full. Such an approach obviously leads to a suboptimal vehicle configuration but was required to match up the sizes of the booster and the orbiter to arrive at a true bimese TSTO configuration used in this study.

The schematic diagram of the attachment of the orbiter to the booster is shown in Fig. 4. The booster is attached to the orbiter at two points. Prior to the release, the forward joint is assumed to be a fixed support and the aft joint is assumed to permit rotation in pitch. These struts and the gap measurements are similar in geometry to the Shuttle Orbiter and External Tank attachment system except that the rear strut has a pivot linkage that allows the rotation of the booster relative to the orbiter upon release of the forward joint. This separation sequence is similar to that used in Ref. 10. The estimated mass properties of the two vehicles at staging are presented in Tables I and II. 
Table I. Mass Properties at Staging for the Mach 3 LGBB-Bimese Vehicle

\begin{tabular}{ccc}
\hline \hline Property & Orbiter & Booster \\
\hline Weight, lbf & $2,909,000$ & 300,000 \\
Total thrust & $4,879,000$ & 0 \\
$x_{\mathrm{cg}}, \mathrm{ft}$ & 197.6 & 130.0 \\
$I_{x x}$, slugs- $\mathrm{ft}^{2}$ & $20,900,000$ & $3,360,000$ \\
$I_{y y}$, slugs- $\mathrm{ft}^{2}$ & $245,000,000$ & $39,400,000$ \\
$I_{z z}$, slugs- $\mathrm{ft}^{2}$ & $245,000,000$ & $39,400,000$ \\
\hline \hline
\end{tabular}

Table II. Mass Properties at Staging for the Mach 6 LGBB-Bimese Vehicle

\begin{tabular}{lll}
\hline \hline Property & Orbiter & Booster \\
\hline Weight, lbf & $2,230,000$ & 476,000 \\
Total thrust & $4,899,000.0$ & 0 \\
$x_{\text {cg }}, \mathrm{ft}$ & 197.6 & 130.0 \\
$I_{x x}$, slugs- $\mathrm{ft}^{2}$ & $16,000,000$ & $5,330,000$ \\
$I_{y y},{\text { slugs- } \mathrm{ft}^{2}}^{2}$ & $188,000,000$ & $62,600,000$ \\
$I_{z z},{\text { slugs- } \mathrm{ft}^{2}}^{2}$ & $188,000,000$ & $62,600,000$ \\
\hline \hline
\end{tabular}

\section{A. Proximity Aerodynamic Characteristics and Development of Aerodynamic Database}

The longitudinal stage-separation aerodynamic coefficients depend on the relative location of the two vehicles as characterized by three variables $\square x, \square z$ and $\square \square$. The dependence of stage-separation aerodynamic coefficients on $\square x$, $\square z$ and $\square \square$ is in addition to their usual dependence on Mach and $\square$. Sketches showing the relative locations of the two vehicles in the wind tunnel tests and corresponding orientations in flight are presented in Fig. 5. The separation distances $\square x, \square z$ are measured with respect to orbiter coordinator system. Note that $\square x$ is negative when the booster is aft of the orbiter.

The proximity aerodynamic database was developed using the data from the stage separation wind tunnel tests conducted in the NASA Langley's UPWT (Unitary Plan Wind Tunnel) at Mach 3 and the NASA Langley's 20-Inch Mach 6 Tunnel. Some Mach 3 stage separation tests were also conducted in the Aerodynamic Research Facility (ARF) at NASA's Marshall Space Flight Center (MSFC). The MSFC test data ${ }^{14}$ was used as a reference but not in the development of the aerodynamic database discussed in this study. A brief description of the Langley's stage separation tests in UPWT and 20-Inch Mach 6 Tunnel is presented in this paper. Detail descriptions of the test facilities, support hardware, models, instrumentation and test procedure are available in Ref. 12. The incremental aerodynamic coefficients for the elevon deflections in proximity conditions were not available for either of the stage separation tests. In view of this, Mach 3 elevon deflection data obtained from isolated LGBB model tests in the Langley UPWT (Mach range: 1.6 to 4.5) was used. Such isolated LGBB elevon data for Mach 6 was not available. In the absence of a better alternative, the available Mach 4.5 UPWT elevon deflection data was used as applicable for Mach 6 conditions. It is possible that isolated elevon incremental coefficients differ from those in proximity. This issue was not addressed in this study.

The Mach 3 stage separation tests were conducted in NASA-Langley UPWT facility. The UPWT is a closedcircuit, continuous flow, pressure tunnel with two test sections that are nominally $4 \mathrm{ft}$ by $4 \mathrm{ft}$ in cross section and seven $\mathrm{ft}$ long. The Mach number range is 1.5 to 2.86 in Test Section I and 2.3 to 4.63 in Test Section II. Two LGBB $1.75 \%$ scale models were used. One LGBB model designated as the orbiter (bottom) model was always held at a fixed location and held fixed at $\square=0$. The other test model designated as the booster (top) model was moved in $\mathrm{x}$ (aft) and in $\mathrm{z}$ (vertical) directions. All the $\mathrm{x}$ and $\mathrm{z}$ traverses were done for two values of angles of attack, 0 and $5 \mathrm{deg}$. A schematic illustration of the LGBB-bimese Mach 3 test matrix is presented in Fig.6.

The Mach 6 stage separation tests were conducted in the Langley 20-Inch Mach 6 Tunnel. Two 1.21\% scale LGBB models were used, one as booster model and the other as orbiter model. All $\mathrm{x}$ movements were achieved by moving the booster (top) model aft of the orbiter (bottom) model and $\mathrm{z}$ movements by lowering the orbiter model from the mated position. A schematic illustration of the model setup and the test matrix for Mach 6 testing is presented in Fig. 7. All $\mathrm{x}$ and $\mathrm{z}$ separations were run at $\square \square=0$ and $\square \square=5 \mathrm{deg}$. At each of the nominal $\mathrm{x}$ and $\mathrm{z}$ locations, both models were simultaneously swept through an angle of attack range using the tunnel strut angle of attack mechanism so that $\square$ varied for each model whereas $\square \square, \square x$ and $\square z$ remain fixed at their nominal values. However, for $\square \square=5$ deg., the actual values $\square x$ and $\square z$ are slightly different due to the rotation in pitch. The angle of attack range was about $-7 \mathrm{deg}$. to $+7 \mathrm{deg}$.

It is necessary to note that for stage separation wind tunnel testing, the direction and magnitude of velocity are identical for both orbiter and booster models. In actual flight post separation, this is not always true. The differences in velocity magnitudes amount to differences in flight Mach numbers and the differences in directions amount to differences in flight path angles. Therefore, some errors are likely to be introduced in the simulations based on these 
stage separation wind tunnel test data, specially if the Mach numbers and flight path angles of the two separating vehicles differ considerably.

The test parameters for Mach 3 and mach 6 stage separation tests are summarized in Table III. The separation distances $\square \mathrm{x}$ are negative in Table III because the booster was always located aft of the orbiter.

To illustrate the physical nature of aerodynamic interference, sample schlieren photographs are presented in Fig. 8 and 9. In the mated condition $(\square x=\square z=0)$ for $\square \square=0$, the mutual interference is characterized by a channel like flow between the two bodies and the bow shock waves of each body impinge on the other resulting in multiple reflections. As the two bodies move short distance apart in $\mathrm{x}$ and $\mathrm{z}$ directions, the channel like flow is not observed. Instead, the mutual interference is mainly determined by bow shock impingements and their reflections. It is interesting to note that the orbiter falls out of booster's influence much earlier than the booster going out of orbiter's influence. For example, for $\square x=0.4, \square z=0.25$, the orbiter is nearly out of booster's influence whereas the booster is still under the orbiter's influence. The shock intersections affect surface pressure distribution causing it to rise over the downstream part of the body resulting in significant variations in normal force and pitching moment coefficients. The flow pattern over the LGBB-Bimese models at Mach 6 has similar features but shock angles are much steeper as shown in Fig. 9.

The isolated LGBB aerodynamic coefficients at Mach 3 and Mach 6 are presented in Fig. 10. To illustrate the physical nature of variation of longitudinal aerodynamic coefficients in the proximity, wind tunnel test data for $\square=0$ and $\square=0$ are presented in this paper. In Figs. 11-16, the total coefficients are presented for Mach 3 case. However, the test data for Mach 6 was in the form of incremental coefficients with respect to the corresponding isolated condition and these incremental coefficients are presented in Fig. 17.

\section{B. Simulation of Staging Maneuvers}

The simulation of staging maneuvers was done using ADAMS ${ }^{\circledR}$ solver, an industry standard package for solving multi-body dynamic problems ${ }^{15}$. The user does not have to input the governing equations of motion to ADAMS ${ }^{\circledR}$ for vehicle motion during stage separation but needs to provide mathematical models of the aerodynamic and other external forces/moments acting on each of the vehicle during stage separation. ADAMS ${ }^{\circledR}$ assembles coupled/constrained equations of motion for each vehicle based on the user supplied inputs and generates solution to those equations as per user requests. To simplify the process of using ADAMS ${ }^{\circledR}$ for solving stage separation problems, NASA Langley has developed a MATLAB-based front and back end, called ConSep to ADAMS ${ }^{\circledR}$ solver. ConSep derives its heritage from SepSim, a front-and-back-end to ADAMS ${ }^{\circledR}$ for X-43A (Hyper-X) stage separation. An independent verification of the ADAMS ${ }^{\circledR}$ predictions of the X-43A stage separation ${ }^{16}$ was conducted and the two results were found to be in close agreement. This exercise confirms that ADAMS ${ }^{\circledR}$ sets up and solves the equations of motion for stage separation problems in an acceptable manner.

ConSep allows the user to setup the stage separation problems in a simple manner. It converts the user inputs into the model specifications used by ADAMS, initiates ADAMS ${ }^{\circledR}$ solver and post-processes the ADAMS ${ }^{\circledR}$ output to express the simulation results in a convenient form. ConSep is designed to allow the user to link aerodynamic mathematical models, aerodynamic data tables, interpolation routines, model attachment points/joints, separation forces due to reaction jets or piston type devices, closed-loop proportional and derivative (PD) control, actuator dynamics, atmospheric winds, engine gimbals etc. to ADAMS ${ }^{\circledR}$ solver. ConSep is also designed to permit the user to study the effect of variations in selected input parameters and also perform Monte Carlo studies. The main advantage of ConSep is that user does not have to be trained in $\mathrm{ADAMS}^{\circledR}$ to use it for solving stage separation problems. Additional information on ConSep is available in Ref. 17.

In this study, simple aerodynamic separation aided by active closed-loop control of elevons on both vehicles was attempted for Mach 3 staging. Separation forces or thrusters were not used. For Mach 6 staging aerodynamic separation was not feasible and separation thrusters were used. At staging, the orbiter was assumed to be thrusting but the booster not. The staging event starts with the release of the forward joint permitting the booster to rotate about the aft joint. The aft joint was released when a specified events, such as $\square \square$ or time reaching a specified value, occurred letting the booster free to go. 
The inputs to ConSep/ADAMS simulation of LGBB-Bimese stage separation were as follows: definition of body-fixed coordinate system for each vehicle in relation to the ground-fixed system (North-East-Down) defined in ADAMS via Euler angles, mass, inertia, center of gravity of each vehicle in its body-fixed coordinate system, initial altitude, velocity, flight path angle, angle of attack of each vehicle, mathematical model of aerodynamic forces and moments in proximity and free flight, location of the moment reference point for each vehicle, tables of proximity aerodynamic forces and moment coefficients as functions of $\square x, \square z, \square$ and $\square \square$ (for Mach 3 and 6), aerodynamic coefficients for isolated or free flight conditions at Mach 3 and 6, incremental aerodynamic coefficients for elevon

Table IV. Initial Conditions for LGBB-Bimese Vehicles

\begin{tabular}{ccc}
\hline \hline Parameter & Mach 3 Staging & Mach 6 Staging \\
\hline Altitude, $\mathrm{ft}$ & 85000 & 150000.0 \\
Velocity, ft/sec & 2924.6 & 6586.6 \\
Dynamic Pressure, lb/sft & 287.0 & 75.0 \\
Flight Path Angle $L, \mathrm{deg}$ & 53.0 & 30.0 \\
// (booster), deg & 0.0 & 0.0 \\
// (orbiter), deg. & 0.0 & 0.0 \\
Atmospheric Model & US Standard Atmosphere 1962 & US Standard Atmosphere 1962 \\
Separation thrust & 0.0 & 750000.0 \\
Simulation time, sec & 6.0 & 6.0 \\
Integration step size, sec & 0.01 & 0.01 \\
Front Joint Release, sec & 0.1 & 0.1 \\
Aft-Joint Rotation, sec & 0.1 & 0.1 \\
Aft-Joint Release, sec & $\square \square=1.0$ deg & $\square \square=1.0$ deg (Baseline) \\
& & $\mathrm{t}=0.1 \mathrm{sec}$ (Nominal and all other cases) \\
\hline
\end{tabular}

deflections at Mach 3 and 6, atmospheric model, location of the separation motors, magnitude and direction of net thrust, location of joints/attachment points and degrees of freedom for each joint, time/event for the partial/complete release of front and aft joints, models of actuators for aerodynamic control surface (elevons) of each vehicle, gains for closed-loop PD controller, time for starting and stopping the integration of equations of motion, step size and accuracy of integration. The initial conditions and other parameters used for the stage separation simulations are presented in the following Table IV.

Aerodynamic Forces and Moments

The axial force, normal force and pitching moment are defined as follows:

$$
\begin{aligned}
& F_{x}=\square \frac{1}{2} \square V^{2} S_{r e f} C_{A} \\
& F_{z}=\square \frac{1}{2} \square V^{2} S_{r e f} C_{N} \\
& M=\frac{1}{2} \square V^{2} S_{r e f} l_{r e f} C_{m}
\end{aligned}
$$

where $S_{\text {ref }}=7527.94 \mathrm{ft}^{2}, l_{\text {ref }}=260.1 \mathrm{ft}$. Note that the body length is used as reference length. The moment reference point was located at $0.681_{\text {ref }}$ from the nose of each vehicle. The Mach number is assumed to be constant during stage separation. With this assumption, the aerodynamic coefficients in proximity during stage separation are functions of angle of attack, relative angle of attack and separation distances can be expressed as follows:

$$
\begin{gathered}
C_{A 1 p}=C_{A 1 p}(\square 1, \square \square, \square x, \square z)+\square C_{A 1, \square k_{1}} \\
C_{A 2 p}=C_{A 2 p}(\square 2, \square \square, \square x, \square z)+\square C_{A 2, \square k_{1}} \\
C_{N 1 p}=C_{N 1 p}\left(\square_{1}, \square \square, \square x, \square z\right)+\square C_{N 1, \mathbb{k}_{1}}
\end{gathered}
$$




$$
\begin{aligned}
& C_{N 2 p}=C_{N 2 p}\left(\square_{2}, \square \square, \square x, \square z\right)+\square C_{N 2, \square k_{2}} \\
& C_{m 1 p}=C_{m 1 p}\left(\square_{1}, \square \square, \square x, \square z\right)+\square C_{m 2, \square k_{1 \square}} \\
& C_{m 2 p}=C_{m 2 p}\left(\square_{2}, \square \square, \square x, \square z\right)+\square C_{m 2, \square k_{2}}
\end{aligned}
$$

Here, the suffix 1 and 2 correspond to booster and orbiter respectively. In this paper, the booster is sometimes referred to as vehicle 1 and the orbiter as vehicle 2 . The suffix $\mathrm{p}$ denotes proximity conditions. When the two vehicles move out of the proximity range and are essentially in isolated or free flight (no interference) conditions, the aerodynamic coefficients are assumed to be given by:

$$
\begin{gathered}
C_{A 1 f}=C_{A 1}\left(\square_{1}\right)+\square C_{A 1, \square k_{1}} \\
C_{A 2 f}=C_{A 2}\left(\square_{2}\right)+\square C_{A 2, \square k_{2}} \\
C_{N 1 f}=C_{N 1}\left(\square_{1}\right)+\square C_{N, \square_{e l}} \\
C_{N 2 f}=C_{N 2}\left(\square_{2}\right)+\square C_{N 2, \square k_{1}} \\
C_{m 1 f}=C_{m 1}\left(\square_{1}\right)+\square C_{m 1, \square k_{1}} \\
C_{m 2 f}=C_{m 2}\left(\square_{2}\right)+\square C_{m 2, \square k_{2}}
\end{gathered}
$$

Here, the suffix f denotes isolated or free condition. Note that $C_{A}=C_{A p}$ in proximity and $C_{A}=C_{A f}$ for isolated or free flight conditions and so on.

Owing to facility/resource limitations, the Langley Mach 3 and Mach 6 proximity test data do not cover sufficiently large values of $\square x$ and $\square z$ so that the aerodynamic coefficients transition smoothly from stage separation (proximity) coefficients to isolated (no interference or free flight) coefficients. In view of this, following assumption was introduced to transition from the available stage-separation aerodynamic coefficients to the isolated aerodynamic coefficients as the vehicles move apart.

$$
\begin{gathered}
C_{A 1 t}=k_{1} C_{A 1 f}+\left(1 \square k_{1}\right) C_{A 1 p} \\
C_{A 2 t}=k_{1} C_{A 2 f}+\left(1 \square k_{1}\right) C_{A 2 p} \\
C_{N 1 t}=k_{1} C_{N 1 f}+\left(1 \square k_{1}\right) C_{N 1 p} \\
C_{N 2 t}=k_{1} C_{N 2 f}+\left(1 \square k_{1}\right) C_{N 2 p} \\
C_{m 1 t}=k_{1} C_{m 1 f}+\left(1 \square k_{1}\right) C_{m 1 p} \\
C_{m 2 t}=k_{1} C_{m 2 f}+\left(1 \square k_{1}\right) C_{m 2 p}
\end{gathered}
$$

In the proximity region, $k_{1}=0$ and for isolated or free flight condition, $k_{1}=1$. In the transition region, $k_{1}$ varies linearly from 0 to 1 . The transition region is assumed to consist of two concentric ellipses, an inner ellipse and an outer ellipse defined empirically using the stage separation test data as guide. Both the ellipses are centered at the moment reference point of each vehicle and move with the vehicles. The parameter $k_{1}$ is assumed to vary linearly from 0 at the inner ellipse to 1 at the outer ellipse. These concepts are illustrated in Figures 18. Note that the forward 
halves of the ellipses attached to the orbiter and aft halves attached to the booster are not used in the present implementation of this concept.

Constraints: The available stage separation test data are limited in $\square$ and $\square \square$ values as shown in Table III. The extrapolation outside the database limits was not permitted. In view of this, a constraint was imposed on simulations that each vehicle's $\square$ and $\square \square$ remain within the limits of the proximity databases, that is, $0<\square \square 5.0$ deg and is $0<\square \square \square 5.0 \mathrm{deg}$,

Criteria for Safe Separation: The criteria for a successful stage separation were as follows: (a) no vehicle recontact and, (b) booster stays out of the orbiter's engine plume. It was estimated that the orbiter's plume is correctly expanded for ambient pressure/altitude conditions for both Mach 3 and Mach 6 staging vehicles. Hence, the combined diameter of the orbiter engines would be approximately equal to the vehicle base diameter which is 28.6 $\mathrm{ft}$. However, to be on the conservative side, it is assumed that the minimum $\square z$ separation to avoid booster contact with orbiter plume be assumed equal to two diameters $(59.2 \mathrm{ft})$ or $\square z / l_{\text {ref }} \geq 0.219$. For the $\mathrm{x}$-separation, the acceptable separation distance was specified as $\square x / l_{\text {ref }} \geq 3.0$.

Animation of the Stage-Separation Event: The Synergistic Engineering Environment (SEE) environment was used to create animations of the staging maneuvers. The SEE used the geometry models of the LGBB and the ConSep output to generate these animations. The geometrical shape of the orbiter engine plume was assumed to be a cylinder of constant diameter equal to base diameter because the exit plume was expanded correctly for both Mach 3 and Mach 6 staging conditions. This plume shape was included in the geometry model of the orbiter. The animation of the staging event provides an effective means for visualization of engine plume interactions or collisions if any. Additional information on SEE is available in Ref. 18.

\section{Results and Discussion}

\section{A. Baseline Separation}

The Mach 3 and Mach 6 separation trajectories with zero elevon deflections and zero separation-thrust are presented in Figs. 19 and 20. These two cases are termed baseline separations. The simulation time was selected as 6 $\mathrm{sec}$ with an integration step size of $0.01 \mathrm{sec}$. This duration and step size were considered satisfactory for the simulation of the stage separations discussed in this study.

For both Mach 3 and Mach 6 staging, both booster experiences positive normal force coefficient and positive pitching moment coefficients in the mated conditions (Figs. 11 and 14 for $\square \mathrm{x}=\square \mathrm{z}=0$ ). As a result, when the forward joint was released at $\mathrm{t}=0.1 \mathrm{sec}$, the booster starts to rotate nose-up about the aft joint and its angle of attack starts slowly increasing. When the relative angle of attack $(П П)$ reached $1.0 \mathrm{deg}$, the aft joint was released setting the booster free to go. The two vehicles move away from each other and separation distances $\square x, \square z$ and $\square \square$ keep increasing. However, the vehicle angles of attack go out of the database limits. In view of this, the baseline cases for both Mach 3 and 6 were not considered to result in successful separations.

\section{Nominal Separation}

For both Mach 3 and Mach 6 separations, active closed-loop, proportional-derivative (PD) control was used. The separation thrusters were used Mach 6 separation. No separation motors were used for Mach 3 separation. These two cases are termed nominal Mach 3 and Mach 6 separations.

A schematic diagram of the PD controller implemented in ConSep/ADAMS is shown in Fig 21. The elevon deflections are now controlled by commanded angle of attack $\square_{c m d}$, instantaneous angle of attack, feed forward $\square_{\text {e,bias }}$, pitch rate feedback gains $k_{\square}$ and $k_{q}$. In this study, the feed forward bias was not used. The full range of elevon deflection for which isolated LGBB test data was obtained is $-30 \mathrm{deg}$ to $+20 \mathrm{deg}$. However, for nominal separation, the elevon deflections were limited to -20 to +15 deg deflection to leave some margin for handling off-nominal conditions discussed later. The values of $\square_{c m d}$, gains $k_{\square}$ and $k_{q}$ were determined by trial and error to keep the vehicles within the database limits. The nominal values of the gains are presented in Table VI.

For Mach 3 staging, it can be observed from Fig. 22 that $\square$ and $\square \square$ remain within the limits of the proximity databases. The elevon deflections hit the specified limits initially but subsequently assume smaller values. The axial acceleration of the orbiter is positive due to a net positive thrust but the booster experiences a negative acceleration (deceleration) due to drag. The booster has negative normal acceleration (moving away) but the orbiter has a positive normal acceleration indicating that it tends to move towards the booster. Since the orbiter is much heavier than the booster at staging, the two vehicles continue to move apart. After $6 \mathrm{sec}, \square x / l_{\text {ref }}=-4.0$ and $\square z / l_{\text {ref }}=0.72$, that is the booster is about $1038 \mathrm{ft}$ aft and $189 \mathrm{ft}$ (6.6 diameters) below the orbiter and the two vehicles continue to move 
further apart. Therefore, for the LGBB-Bimese vehicle, a successful Mach 3 staging is feasible using aerodynamic forces and moments acting on the booster and orbiter.

For Mach 3 staging, both orbiter and the booster start with initial velocity of $2924.6 \mathrm{ft} / \mathrm{sec}$ and flight path angle of $53.0 \mathrm{deg}$. At the end of $6 \mathrm{sec}$, the velocities are respectively about $2725 \mathrm{ft} / \mathrm{sec}$ and $3100 \mathrm{ft} / \mathrm{sec}$ corresponding to Mach numbers of about 2.8 and 3.2. The flight path angles are $50 \mathrm{deg}$ and $51 \mathrm{deg}$ respectively for the booster and the orbiter. As said before, the stage separation wind tunnel test data is based at Mach 3 and applies to cases where the flight path angles of booster and orbiter are equal. The issue of possible errors due to variations in Mach number and flight path angles is not addressed in this study.

For Mach 6 staging, simple aerodynamic staging was not feasible, apparently because the freestream dynamic pressure at $150,000 \mathrm{ft}$ altitude is about $1 / 4^{\text {th }}$ of that at $85,000 \mathrm{ft}$ altitude for Mach 3 staging (see Table IV). Therefore, booster separation motors producing a combined thrust of $75000 \mathrm{lbs}$ acting for a duration of $0.5 \mathrm{sec}$ immediately after the release of aft joint were used. This thrust was assumed to be applied in the negative $O z_{1}$-direction of the booster body-fixed coordinate system (Fig. 5). A higher magnitude of separation thrust certainly helps stage separation but increases the weight penalty due to the inclusion of separation motors, Using the performance and mass property data of the separation motors used on the Solid Rocket Boosters of the Space Shuttle, ${ }^{19,20}$ the weight penalty of carrying the suite of separation motors producing a combined thrust of $750,000 \mathrm{lb}$ for a duration of 0.5 sec was estimated to be $5770 \mathrm{lb}$, which is about $1.92 \%$ booster weight at separation. The effect of separation motor plume impingement was not addressed in this study.

The combined use of active elevon control and separation motors results in a successful Mach 6 stage separation as shown in Fig 23. The nominal feedback control parameters for the Mach 6 separation are presented in Table VI. After $6 \mathrm{sec}, \square x / l_{\text {ref }}=-4.8$ and $\square z / l_{\text {ref }}=0.57$, that is the booster is about $1250 \mathrm{ft}$ aft and $150 \mathrm{ft}$ (5.2 diameters) below the orbiter and the two vehicles continue to move further apart.

For both Mach 3 and Mach 6 separations, large values of pitch rate feedback gains were required, particularly for the booster, This brought into question the role of dynamic derivative in pitch $\left(C_{m q}\right)$ in the stage separation simulations. The stage separation test data for $C_{m q}$ is not available. Using DATCOM methods, ${ }^{21}$ for the isolated LGBB vehicle at Mach 3, $C_{m q}$ were estimated to be about -0.32 per radian that is about 300 times smaller than the artificial damping provided by the pitch rate feedback. Hence, no further efforts were made to include dynamic terms in the simulations performed in this study. A similar observation was made by Decker et al. ${ }^{5}$

Table VI. Summary of LGBB-Bimese Simulations

\begin{tabular}{ccc}
\hline \hline Description & LGBB-Mach 3 Staging Vehicle & LGBB-Mach 6 Staging Vehicle \\
\hline Baseline & No active control, no separation motors & No active control, no separation motors \\
Nominal & Active PD control, No separation motors & Active control of elevons, separation of \\
& $K_{\square}=-3, K_{q}=8, \square_{c m d}=2.0 \mathrm{deg}$ & $750,000 \mathrm{lbs}$. \\
Parameter Varrations & Mass, inertia, flight path angle and altitude & $K_{\square}=-5, K_{q}=5, \square_{c m d}=2.0 \mathrm{deg}$ \\
Monte Carlo Runs & at staging & Mass, inertia, flight path angle and \\
& altitude at staging & None
\end{tabular}

\section{Effect of Parametric Variations}

These studies were performed for both Mach 3 and Mach 6 staging LGBB-Bimese vehicles. However, the results will be presented only for Mach 3 staging LGBB-Bimese vehicle because the results were similar for the Mach 6 staging LGBB-Bimese vehicle. The values of the feedback gains were held fixed at their nominal values and the full range of elevon deflections were used for vehicle control during separation.

Effect of variation of mass and inertia

The mass and inertia in pitch of both vehicles varied independently by $\pm 10 \%$ from their nominal values resulting in a combination of 9 cases for each parameter. The results are shown in Figs. 24 and 25. It may be and the nominal Mach 3 feedback controller is capable of handling these variations in mass and inertia and keep the vehicle $\square$ and पD within the database limits. 


\section{Effect of variations in flight path angle and altitude at staging}

The nominal values of flight path angle and altitude at staging are $53 \mathrm{deg}$ and $85000 \mathrm{ft}$ respectively. These were varied by $\pm 10 \mathrm{deg}$ and $\pm 5000 \mathrm{ft}$ respectively. The results are shown in Figs. 26 and 27. It is noted that these variations can be handled by the nominal Mach 3 feedback controller satisfactorily and maintaining vehicle $\square$ and within the database limits.

\section{Monte Carlo Runs}

These studies were performed to evaluate the robustness of the nominal controller to aerodynamic uncertainties when all the other parameters assumed their nominal values. Following a recent study on aerodynamic uncertainties of the X-33 vehicle ${ }^{22}$ the Space Shuttle heritage ${ }^{23-25}$, two types of aerodynamic uncertainties were assumed, tolerances and variations. The tolerances are associated with measurement errors in wind tunnels. The estimated tolerances for Mach 3 stage separation wind tunnel testing are: $C_{N}= \pm 0.0019, C_{A}= \pm 0.0012, C_{m}= \pm 0.00022$. The data suitable for the estimation of variations in the stage separation environment are not available. In the absence of a better alternative, the uncertainties associated with Space Shuttle reentry flight are used as variances in this study: $C_{N}= \pm 0.015, C_{A}= \pm 0.006, C_{m}= \pm 0.003$. The total or net uncertainties were assumed to be sum of tolerances and variances. It may be noted that these uncertainties are very conservative and are often as large as the proximity aerodynamic coefficients themselves.

The results of 200 Monte Carlo runs are presented in Fig. 28. The number of cases which resulted in successful separation $\left(\square z / l_{\text {ref }} \geq 0.2\right)\left(\mathrm{Dz} /\right.$ were 184 and the failures $\left(\left(\square z / l_{\text {ref }} \square 0.2\right)\right.$ were 16 . The number of cases which went outside the database limits ( $\square \square>5.0 \mathrm{deg}$ ) were 51 with a maximum $\square \square$ of $6.59 \mathrm{deg}$. For these 51 cases, the vehicle$\square$ were within the $5 \mathrm{deg}$ limit. Considering that the estimated uncertainties were very much on the conservative side, it is believed that the nominal controller for the Mach 3 staging satisfactorily handles the aerodynamic uncertainties assumed in this study.

\section{Animation of the Staging Event:}

The ConSep output and the LGBB-Bimese vehicle geometry models were input to the SAE to produce animation of the staging event. As said before, the engine plume was assumed to be correctly expanded for both Mach 3 and Mach 6 operating altitudes and was modeled as a solid cylinder extending few diameters from the base of the orbiter. Snap shots of the animation taken at selected time intervals are shown in Fig. 29.

\section{Concluding Remarks}

The analyses and simulation of the staging maneuvers of two TSTO vehicle concepts, one staging at Mach 3 and the other staging Mach 6 were performed to demonstrate the application of the ConSep tool which is being developed as a part of NASA's stage separation tool development activity. The proximity aerodynamic databases were developed using the data from stage separation wind tunnel tests conducted at NASA Langley Research Center. A passive release of the vehicles for Mach 3 and Mach 6 staging did not result in satisfactory stage separation because the vehicle angles of attack and relative angles of attack went very much outside the database limits. For Mach 3 LGBB-Bimese vehicle, aerodynamic separation was feasible using active closed-loop feedback controller. However, for Mach 6 LGBB-Bimese vehicle, aerodynamic staging was not feasible and separation motors were used. Parametric variations in mass, inertia, flight path angle and altitude at staging were investigated. Monte Carlo simulations were performed to evaluate the robustness of nominal controller to aerodynamic uncertainties. The results indicate that the nominal controller satisfactorily handles off-nominal conditions in mass, inertia, flight path angle, altitude at staging and estimated uncertainties in aerodynamic coefficients.

\section{Acknowledgments}

The authors like to greatfully acknowledge Wayne J. Borderlon and Alonzo L. Frost for MSFC stage separation test data and schlieren photographs, Roger Lepsch for ISAT vehicle concepts, Steve Harris and Mark McMillin for geometry, and Scott Angster for animations.

\section{References}

\footnotetext{
${ }^{1}$ Dillenius, M.F.E., Perkins, S.C., and Nixon, D., Pylon Carriage and Separation of Stores, AIAA Progress in Astronautics and Aeronautics: Tactical Missile Aerodynamics-General Topics, M.J.Hemsch, ed., Vol. 141, 1992.

${ }^{2}$ Taylor, R.T., and Alford, W. J, Jr., A wind tunnel investigation of the carry loads and mutual interference effects of $1 / 40$ scale models of the X-15 and B-52 airplanes in combination, NASA TM X-184, December 1959.
} 
${ }^{3}$ Decker, J.P., and Wilhite, A. W., Technology and Methodology of Separating Two Similar Size Aerospace Vehicles Within the Atmosphere. AIAA Paper 1975-29, Jan. 1975.

${ }^{4}$ Decker, J. P., Experimental Aerodynamics and Analysis of the Stage Separation if Reusable Launch Vehicles. NASA-SP148, January 1967.

${ }^{5}$ Decker, J. P., and Gera, J., An Exploratory Study of Parallel-Stage Separation of Reusable Launch Vehicles. NASA TN D4765, October 1968.

${ }^{6}$ Decker, J. P., Aerodynamic Interference Effects Caused by Parallel-Staged Simple Aerodynamic Configuration at Mach Numbers of 3 and 6. NASA TN D-5379, Aug. 1969.

${ }^{7}$ Wilhite, A. W., Analysis of Separation of the Space Shuttle Orbiter from a Large Transport Airplane. NASA TM X-3492, June 1977.

${ }^{8}$ Naftel, J. C., and Wilhite, A.W., Analysis of Separation of a Two-Stage Winged Launch Vehicle. AIAA Paper 86-0195, Jan. 1986.

${ }^{9}$ Naftel, J. C., and Powell, R.W., Aerodynamic Separation and Glideback of a Mach 3 Staged Orbiter. AIAA Paper 90-0223, Jan. 1990.

${ }^{10}$ Naftel, J. C., and Powell, R. W., Analysis of the Staging Maneuver and Booster Glideback Guidance for a Two-Staged, Winged, Fully Reusable Launch Vehicle. NASA TP-3335, 1993.

${ }^{11}$ Pamadi, B.N., Tartabini, P.V., and Starr, B.R.; Ascent, Stage Separation and Glideback Performance of a Partially Reusable Small Launch Vehicle, AIAA Paper 2004-0876.

${ }^{12}$ Murphy, K.J., Buning, P.G., Pamadi, B.N., Scallion, W.I., and Jones, K.M.; Status of Stage Separation Tool Development for Next Generation Launch Vehicle Technologies. AIAA Paper 2004-2595.

${ }^{13}$ Pamadi, B.N., Neirynck, T. A., Covell, P.F., Hotchko, N.J., and Bose, D.M., Simulation and Analyses of Staging Maneuvers of Next Generation Reusable Launch Vehicles, AIAA Paper 2004-5185.

${ }^{14}$ Bordelon, W.J., Frost, A.L., Reed, D.K., Stage Separation Wind Tunnel tests of a Generic Two-Stage-to-Orbit Launch Vehicle, AIAA Paper 2003-4227, July 2003.

${ }^{15}$ Using ADAMS/Solver, Mechanical Dynamics, Inc., 1999.

${ }^{16}$ Tartabini, P.V., Bose, D.M., McMinn, J.D., Martin, J.G., and Stovers, B.K., Hyper-X Stage Separation Trajectory Validation Studies, AIAA Paper 2003-5819.

${ }^{17}$ Bose D.M., and Hotchko, N., Conceptual Level Stage Separation Simulation (ConSep)-Version 1.1 User's Guide, AMA Report No. 02-37 Rev.B, Analytical Mechanics Associates, Hampton, VA, December 2003.

${ }^{18}$ Angster, S., Synergistic Engineering Environment Build II User's Guide Revision E, AMA Report No. 03-31, Analytical Mechanics Associates, Hampton, VA, August 2003.

${ }^{19}$ Boeing. Performance Enhancement Operational Aerodynamic Design Data Book: Launch Vehicle Aerodynamic Data. RSS98D0313, Jan. 28, 1999.

${ }^{20}$ Marshal Space Flight Center. STS36: SRB Preflight Predicted Mass Properties. SRB Mass Properties Status Report No. 64, Addendum D. Dec. 1989.

${ }^{21}$ Pamadi, B.N., Performance, Stability, Dynamics and Control of Airplanes, ${ }^{\text {nd }}$ Ed, AIAA Text Book, 2004, pp.174-175, 187-188.

${ }^{22}$ Cobleigh, Brent R. Development of the X-33 Aerodynamic Uncertainty Model. NASA TP-1998-206544. April 1998.

${ }^{23}$ Young, James C. and Underwood, Jimmy M. The Development of Aerodynamic Uncertainties for the Space Shuttle Orbiter. AIAA Paper 82-0563, 1982.

${ }^{24}$ Boeing Reusable Space Systems/United Space Alliance., Orbiter Operational Aerodynamic Data Book. RSS99D0001, April 2000.

${ }^{25}$ Rockwell International Space Division, Aerodynamic Design Data Book, Vol. 1, Orbiter Vehicle. Downey, CA. Rept. SD 772-SH-0060-1L, Nov. 1977. 

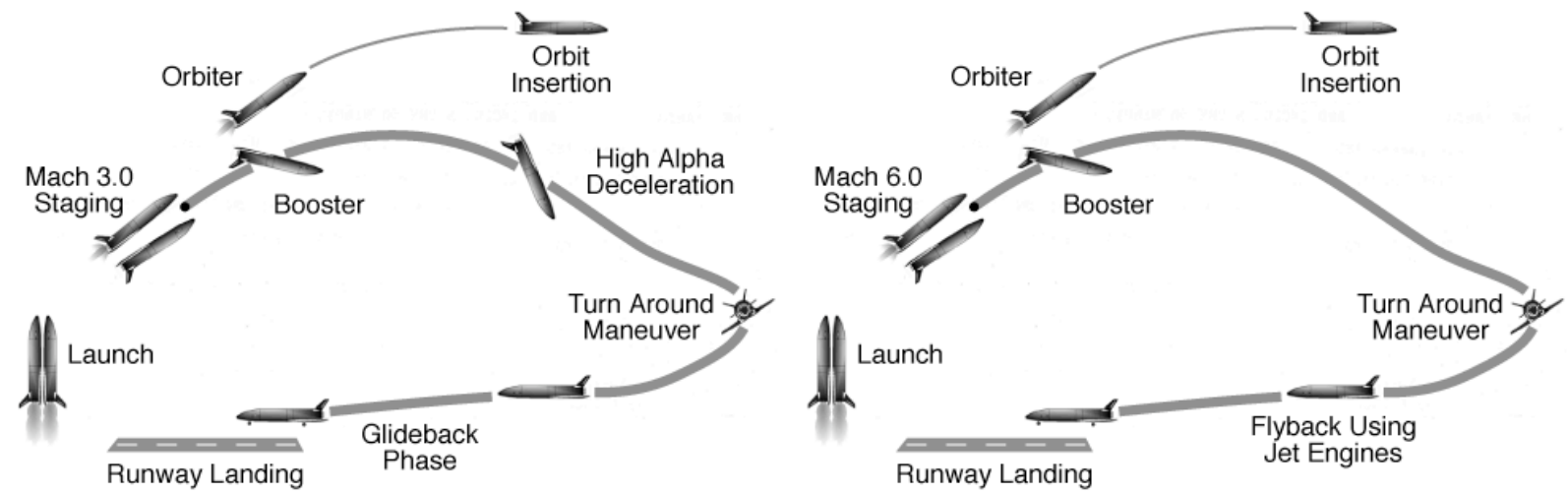

(a)

(b)

Figure 1. Illustration of the flight profiles.

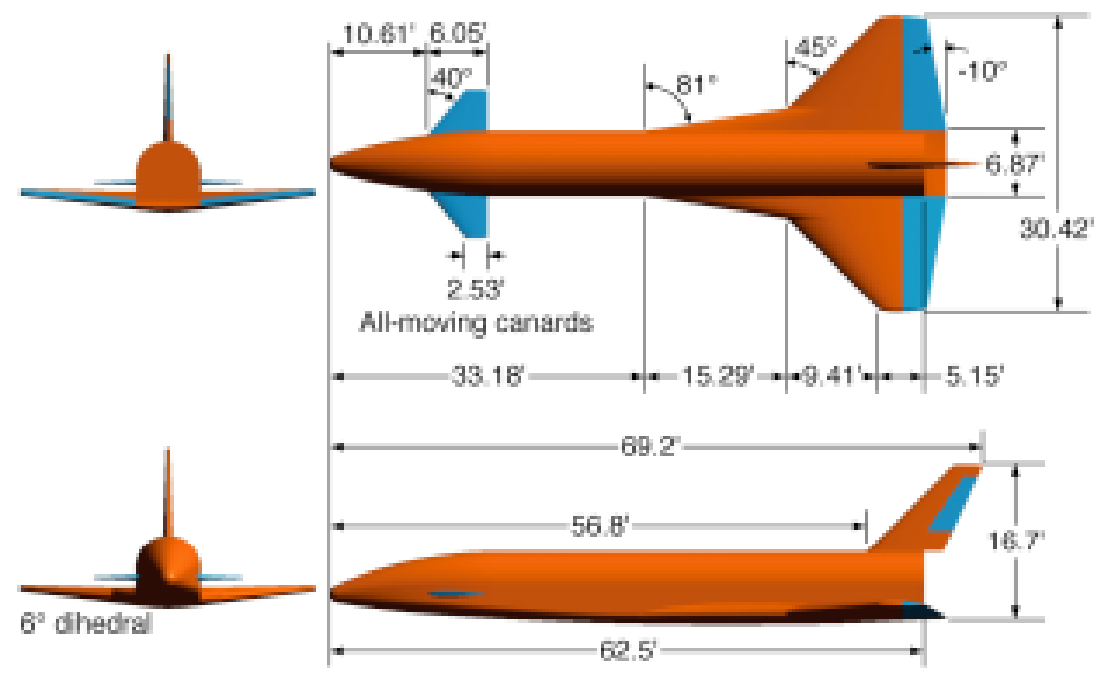

Figure 2. Three-view diagram of the Langley glide-back booster (LGBB).

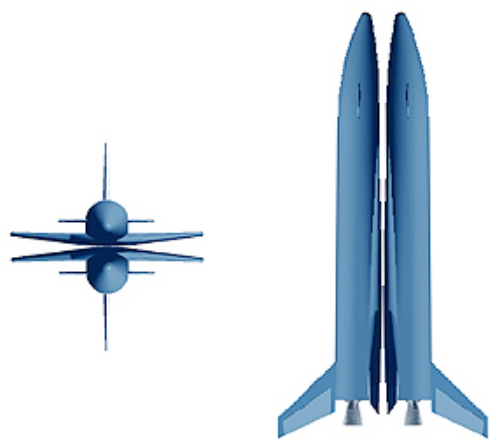

Figure 3. Bimese version of the LGBB TSTO Vehicle. 


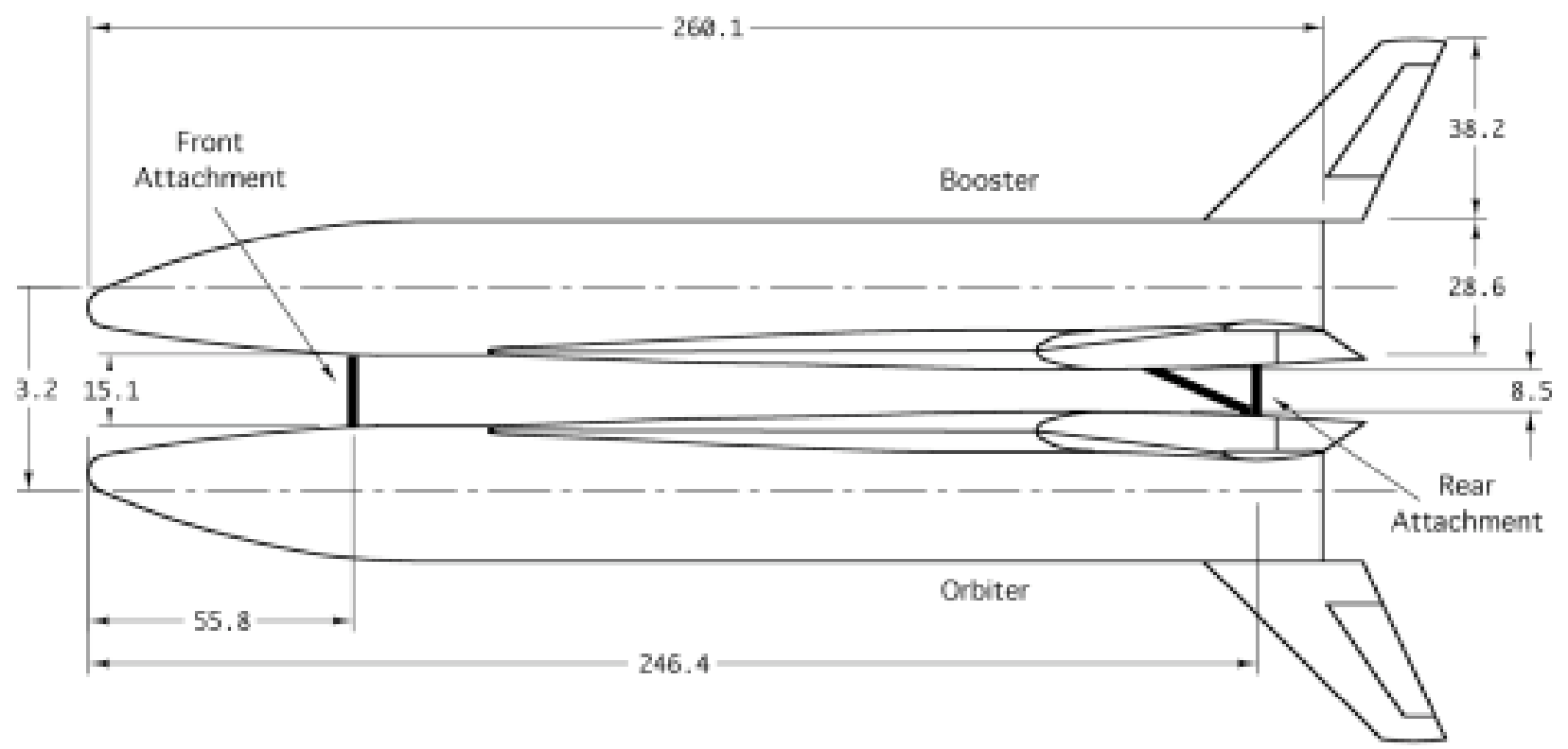

Figure 4. Schematic illustration of the attachment of the booster and the orbiter.
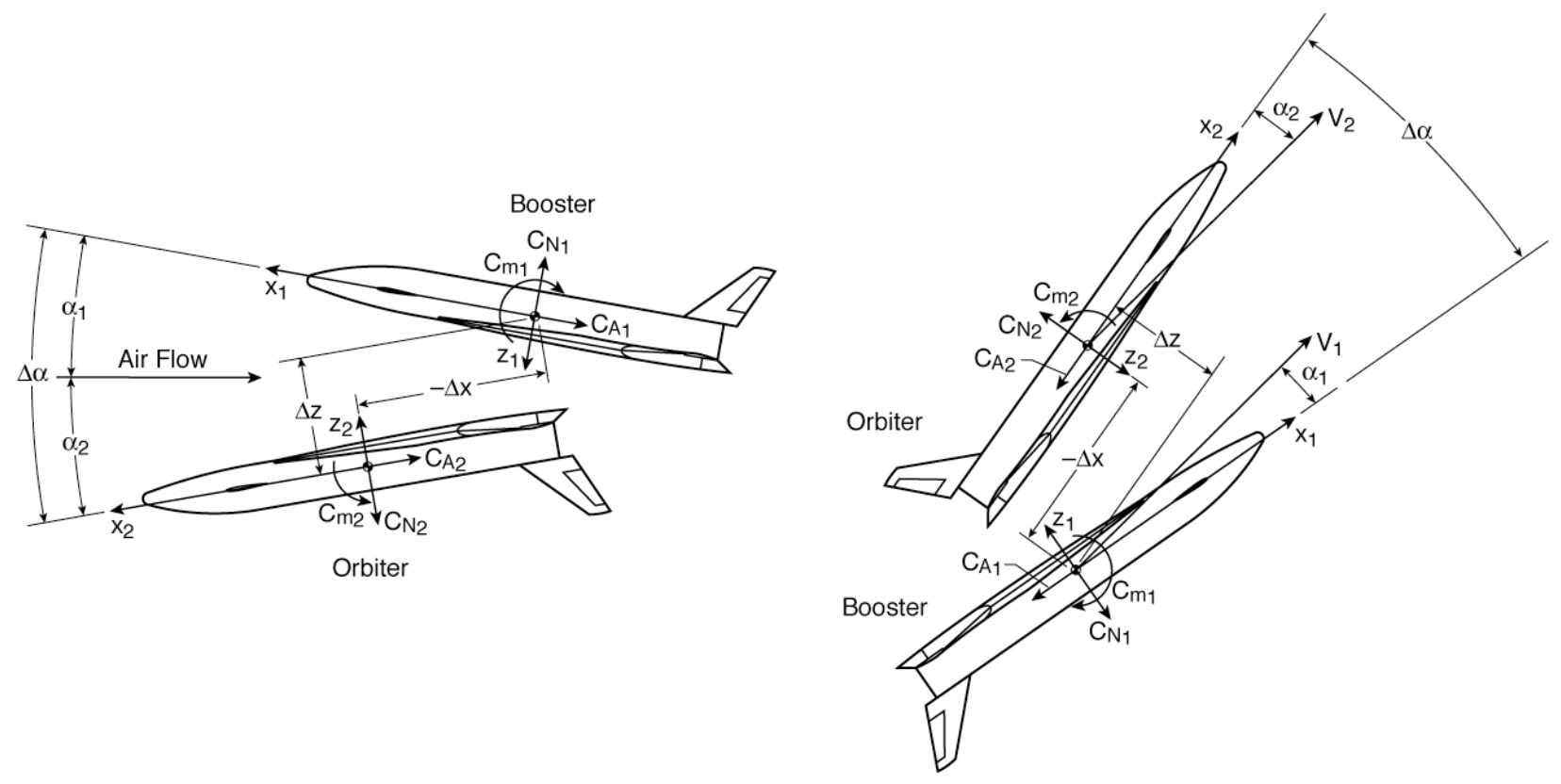

(a) Wind Tunnel Tests

b) Flight

Figure 5. Relative locations of booster and orbiter in proximity. 


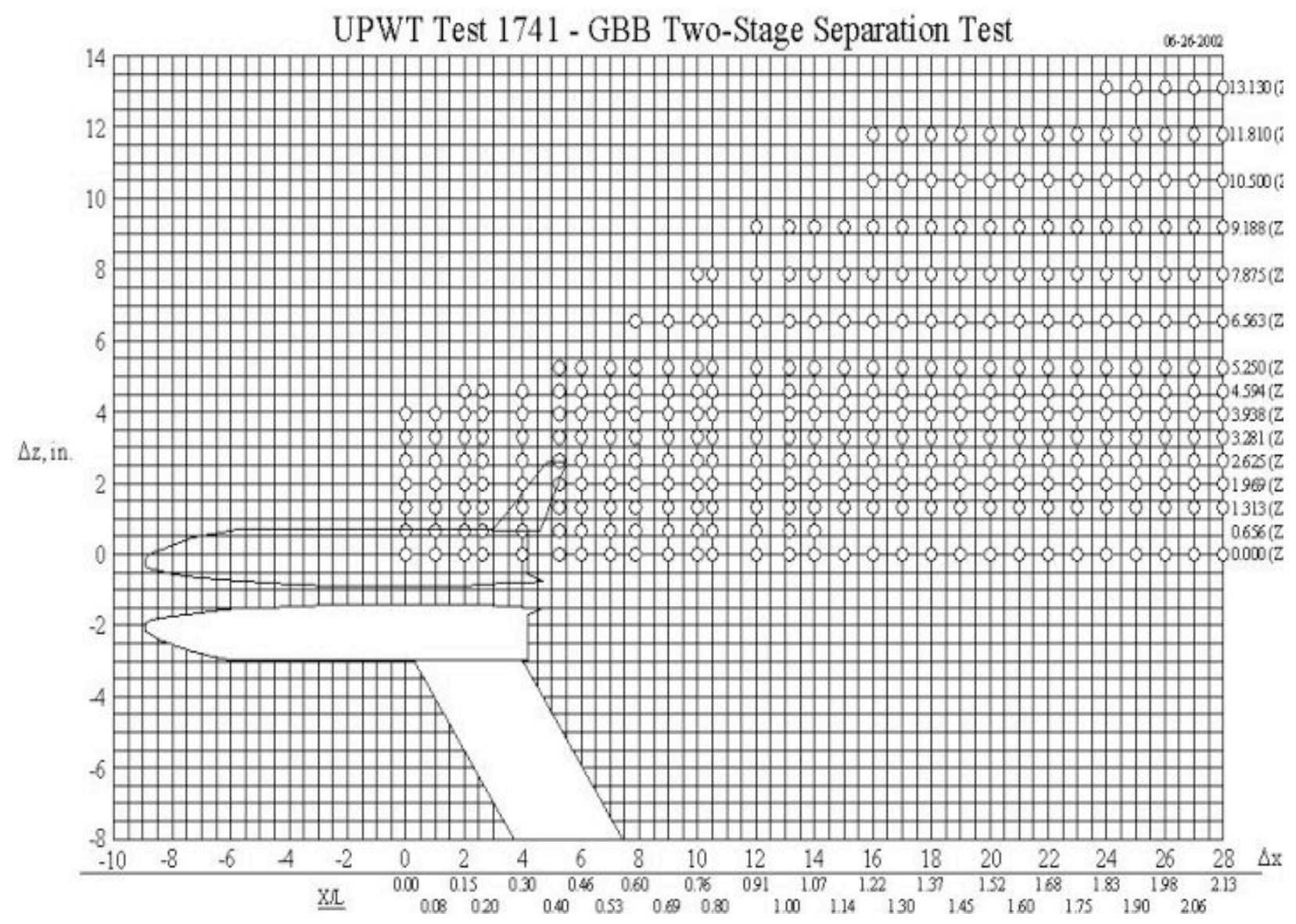

Figure 6. Schematic illustration of LGBB-Beimese UPWT test matrix at Mach 3.

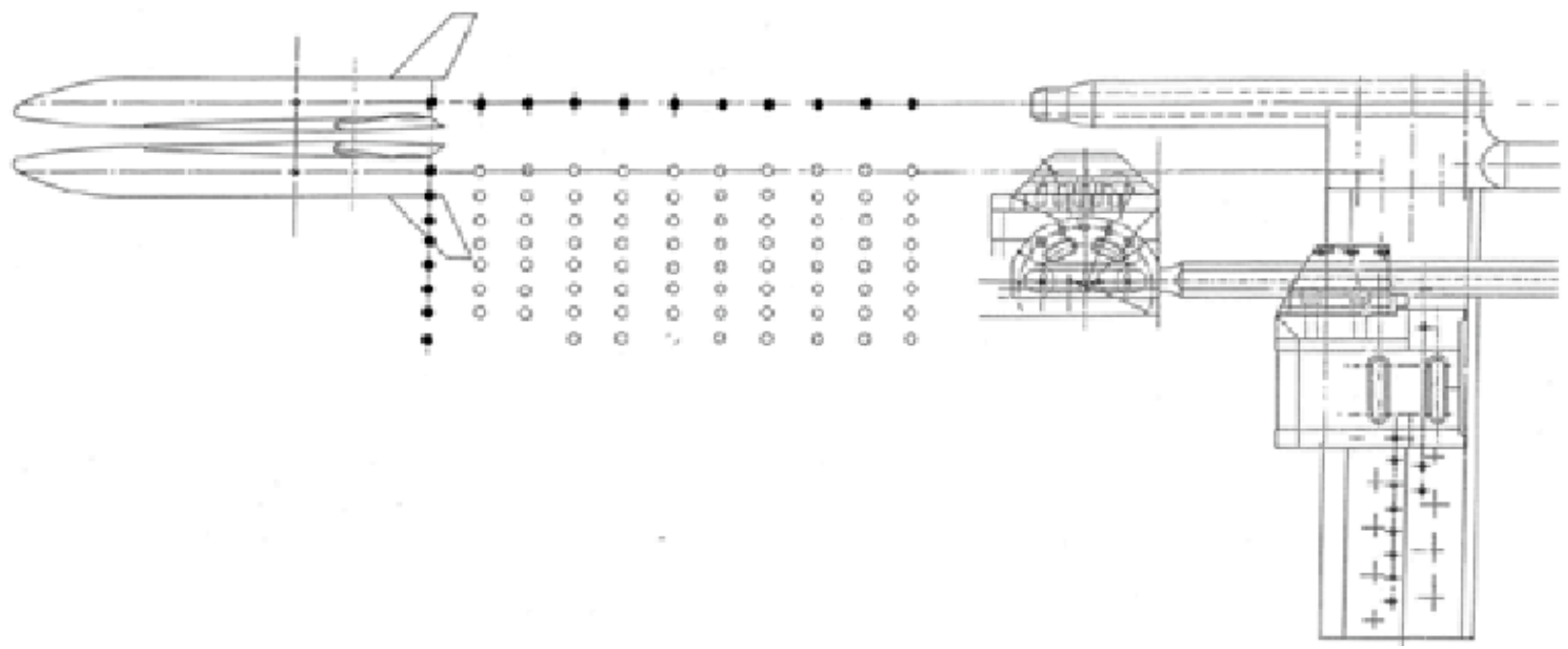

Figure 7. Schematic illustration of the LGBB-Bimese Mach 6 Tunnel test matrix. 


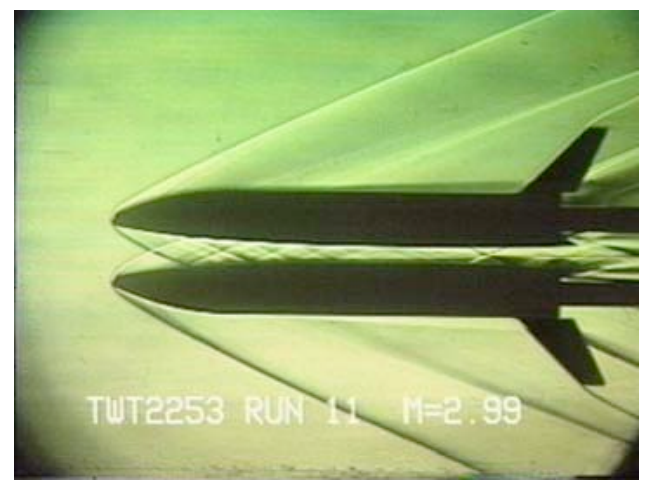

(a) $\square x / l_{r e f}, \square z l_{r e f}=0.0, \square \square=0$

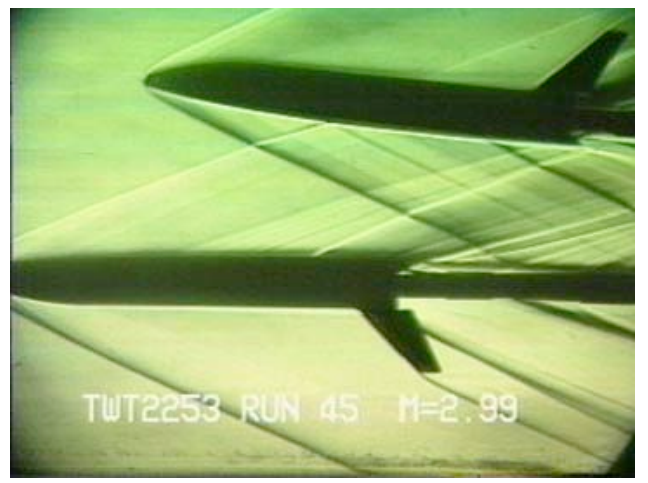

(c) $\square x / l_{r e f}=0.4, \square z / l_{r e f}=0.25, \square \square=5$

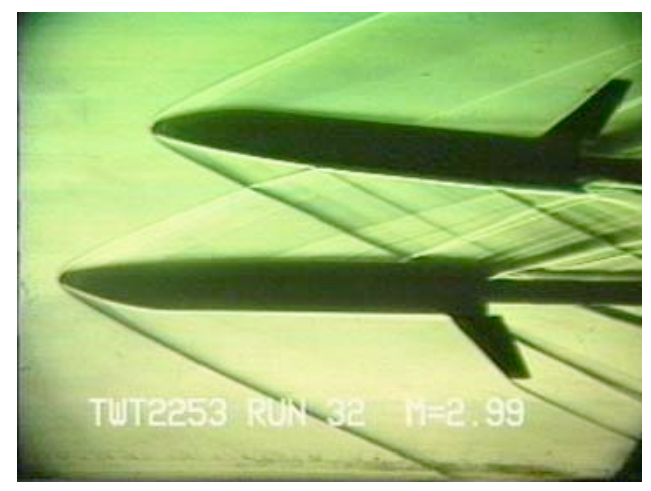

(b) $\square x / l_{r e f}=0.2, \square z l_{r e f}=0.16, \square \square=5$

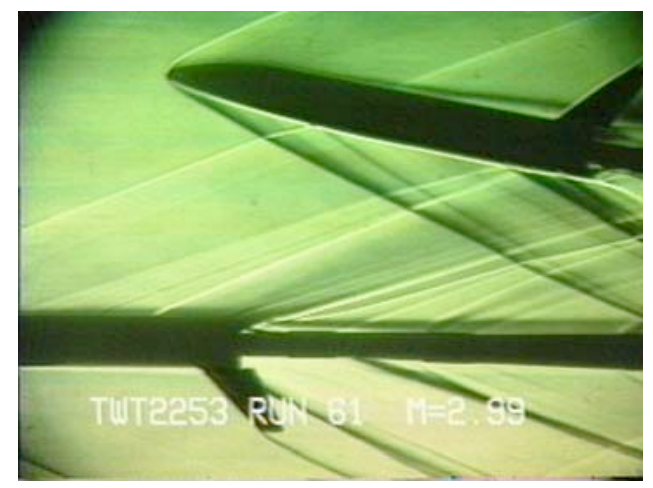

(d) $\square x / l_{r e f}=0.8, \square z l_{r e f}=0.36, \square \square=5$

Figure 8. Schlieren Photographs of the LGBB bimese configurations at Mach 3 stage-separation environement in MSFC Aerodynamic Research Facility. ${ }^{4}$ 

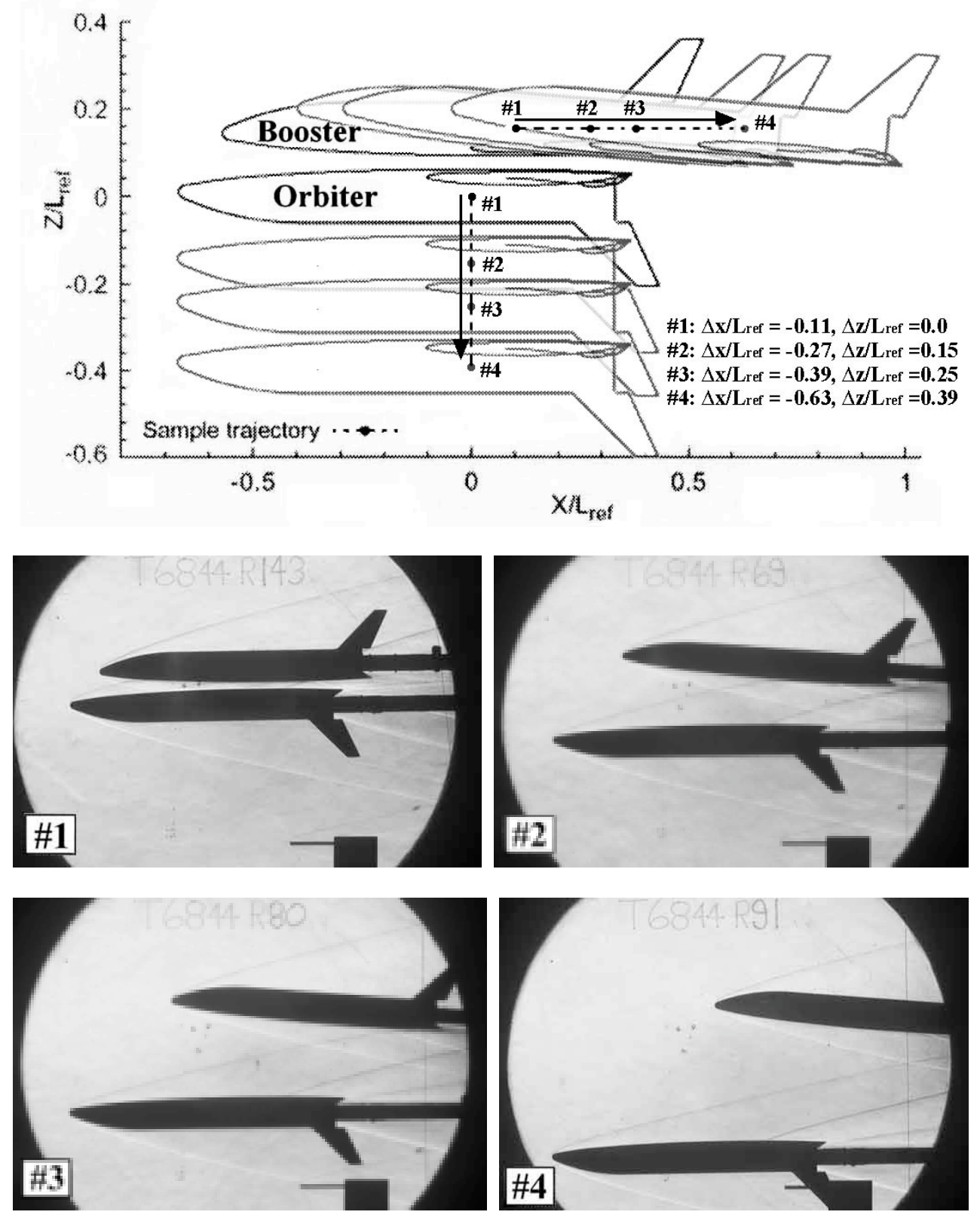

Figure 9. Schlieren Photographs of the LGBB-Bimese configuration in 20-Inch Mach 6 Tunnel. 

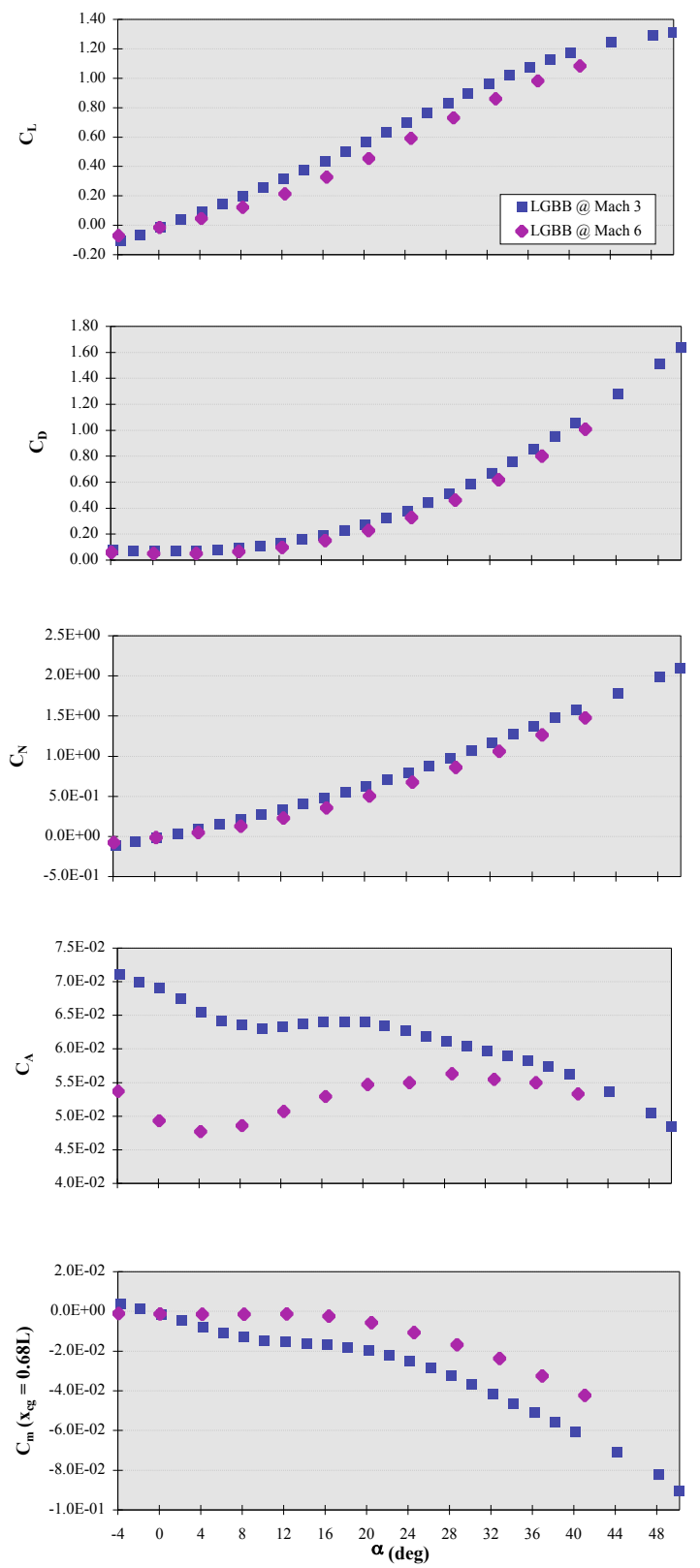

Figure 10: Variation of Isolated LGBB lift, drag, normal and axial force, and pitching moment coefficients with AoA at Mach 3 and 6.
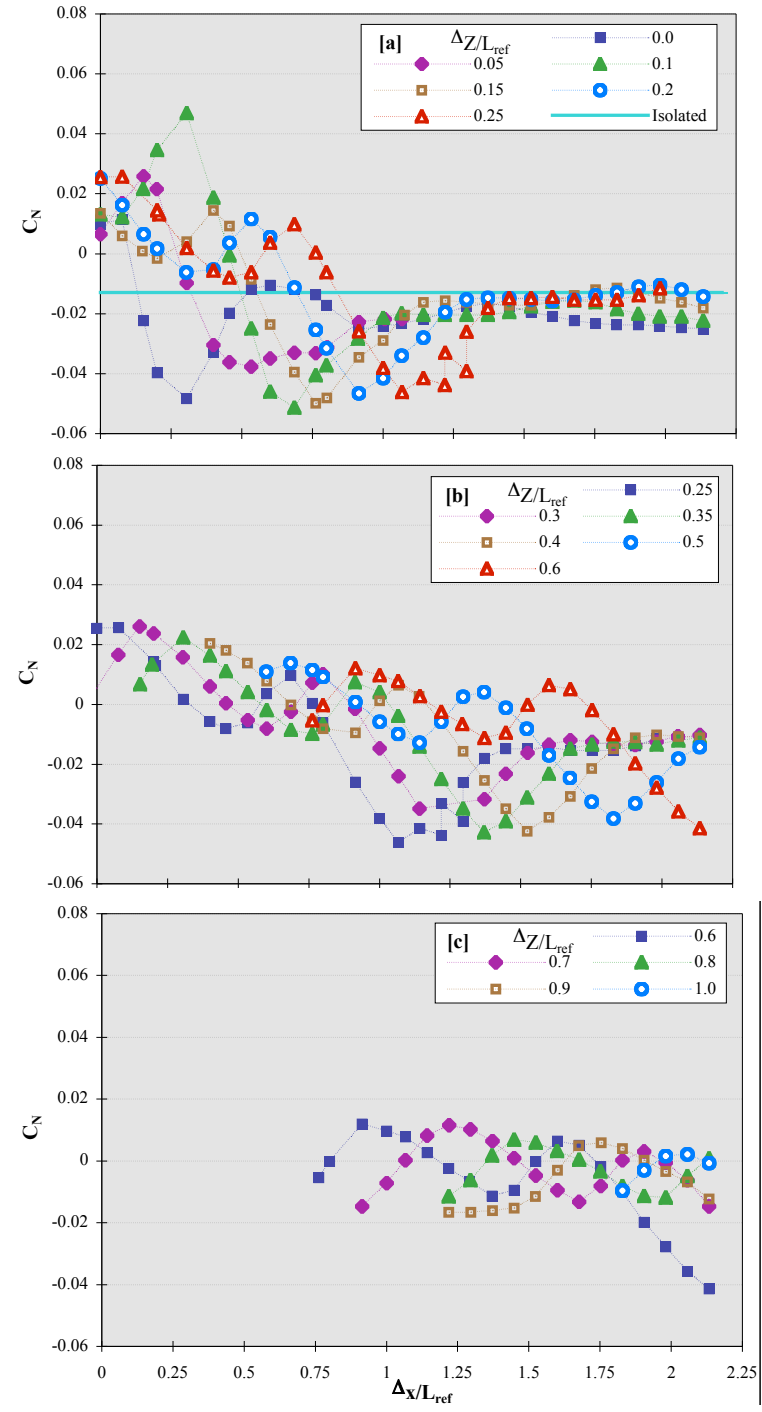

Figure 11: Variation of bimese-booster normal force coefficient with $\square x / L_{\text {ref }}$ and $\square \mathrm{z} / \mathrm{L}_{\text {ref }}$ at Mach 3 for $\square=0, \square \square=0$ degrees.

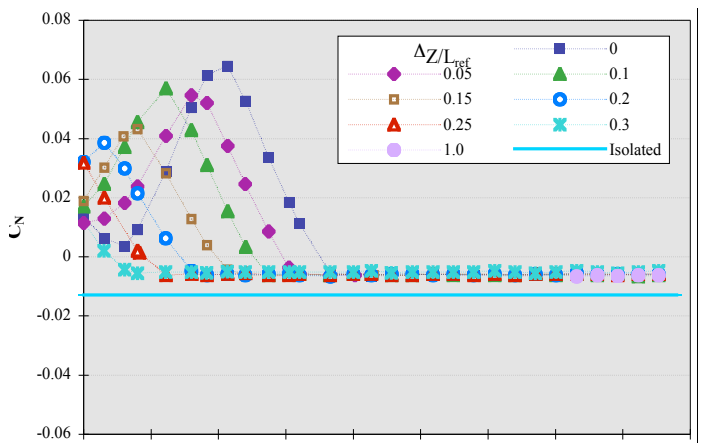

Figure 12: Variation of bimese-orbiter static normal force coefficient with $\square x / L_{\text {ref }}$ and $\square z / L_{\text {ref }}$ at Mach 3 for $\square=0$, $\square \square=0$ degrees. 

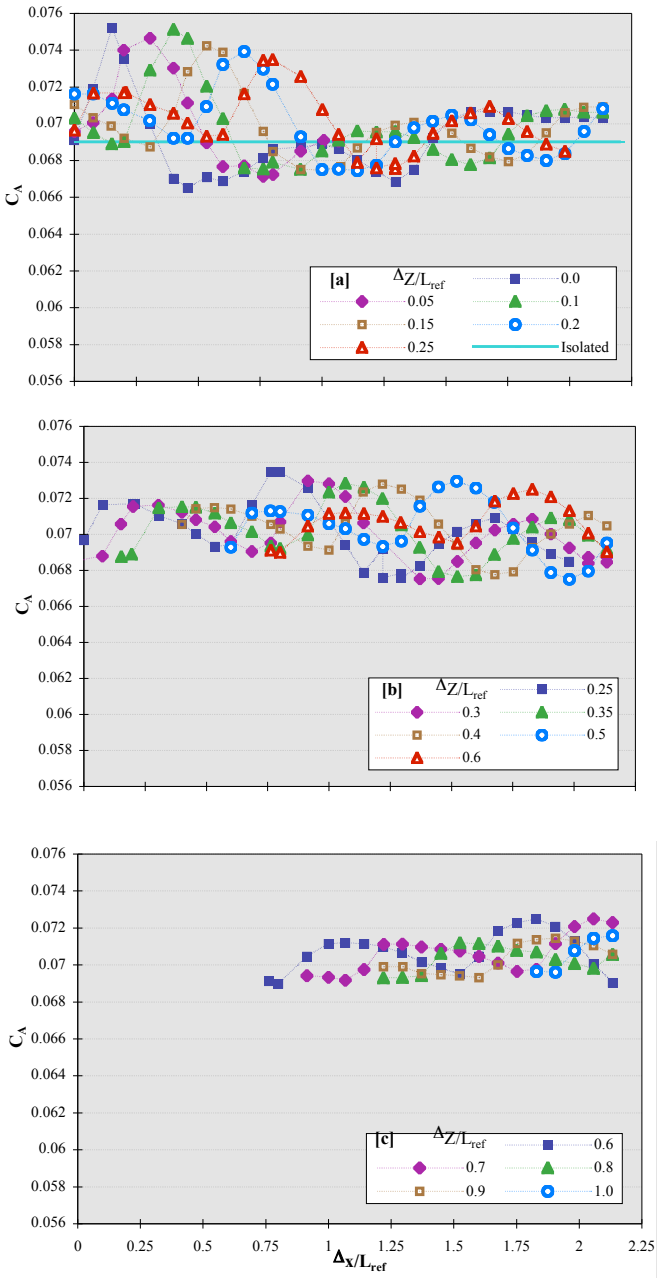

Figure 13: Variation of bimese-booster axial force coefficient with $\square \mathrm{x} / \mathrm{L}_{\text {ref }}$ and $\square \mathrm{z} / \mathrm{L}_{\text {ref }}$ at Mach 3 for $\square=0,0 \square=0$ degrees.

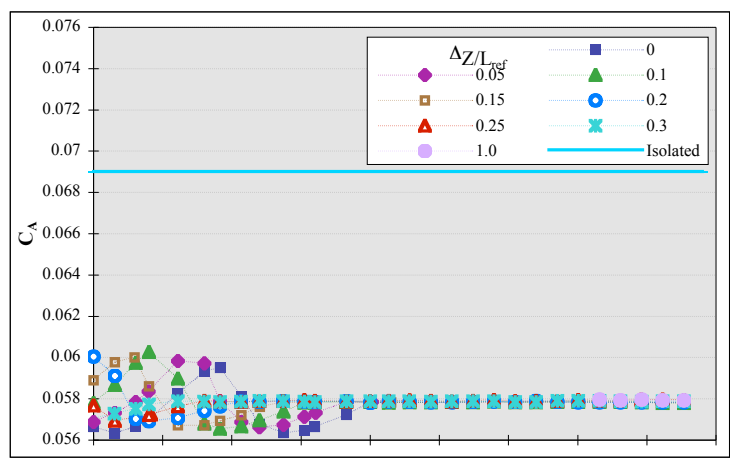

Figure 15: Variation of bimese-orbiter axial force coefficients with $\square x / L_{\text {ref }}$ and $\square z / L_{\text {ref }}$ at Mach 3 for $\square=0,0 \square=0$ degrees.
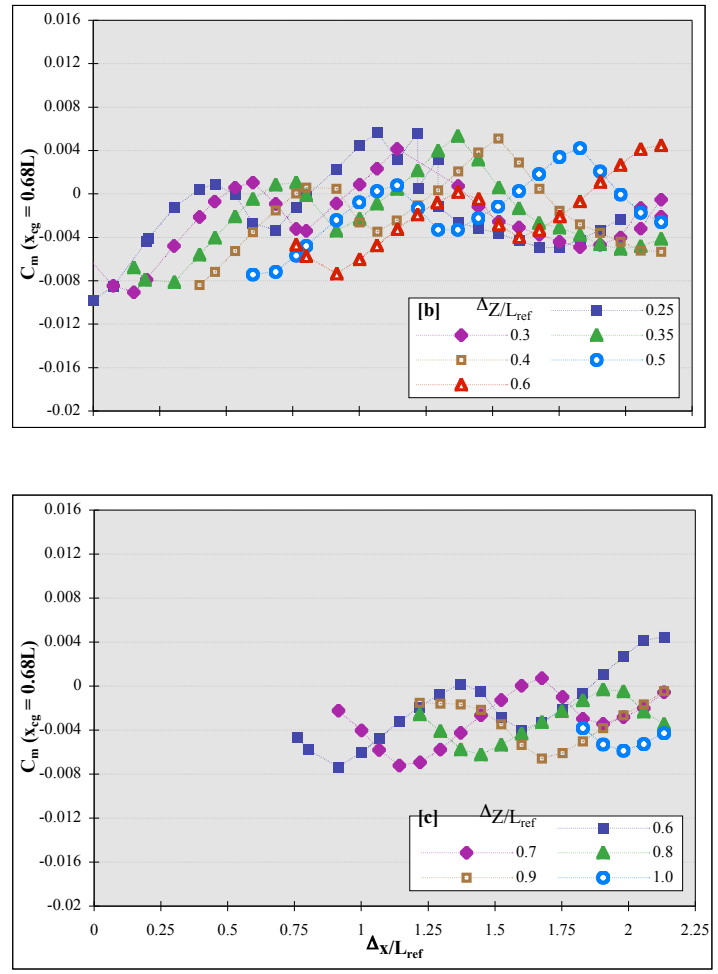

Figure 14: Variation of bimese-booster pitching moment coefficient with $\square x / L_{\text {ref }}$ and $\square \mathrm{z} / \mathrm{L}_{\text {ref }}$ at Mach 3 for $\left.\square=0, \square\right]=0$ degrees.

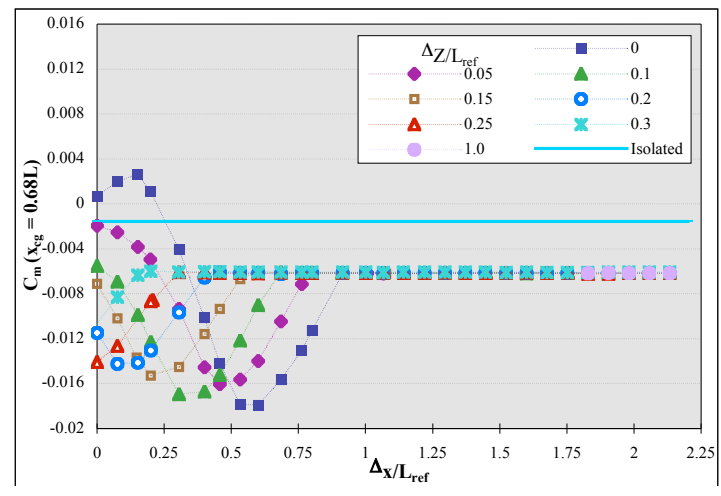

Figure 16: Variation of bimese-orbiter pitching moment coefficients with $\square x / L_{\text {ret }}$ and $\square \mathrm{z} / \mathrm{L}_{\text {ref }}$ at Mach 3 for $\square=0, \square \square=0$ degrees. 

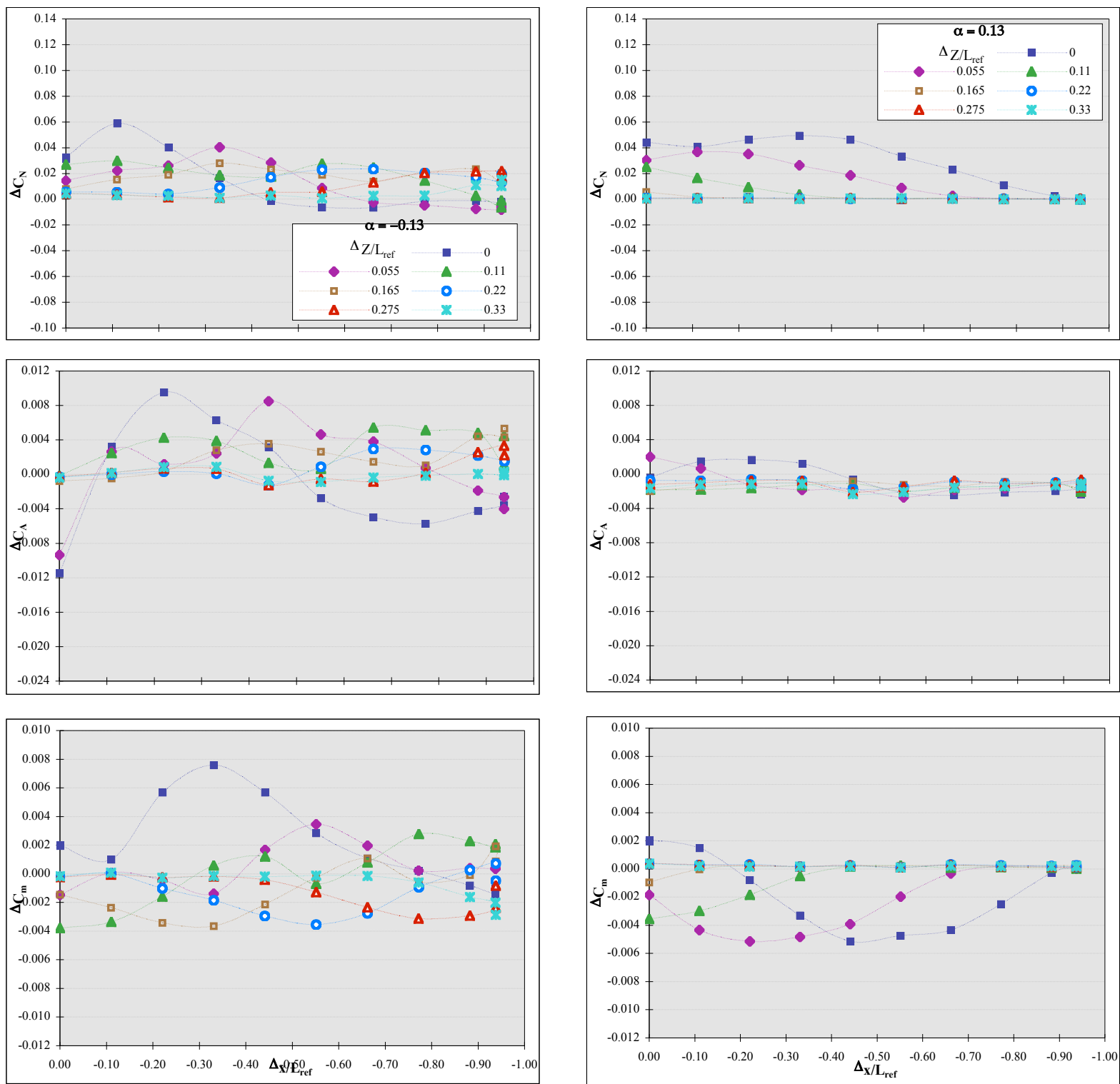

Vehicle 1 (Booster) @ 00 = 0 degrees

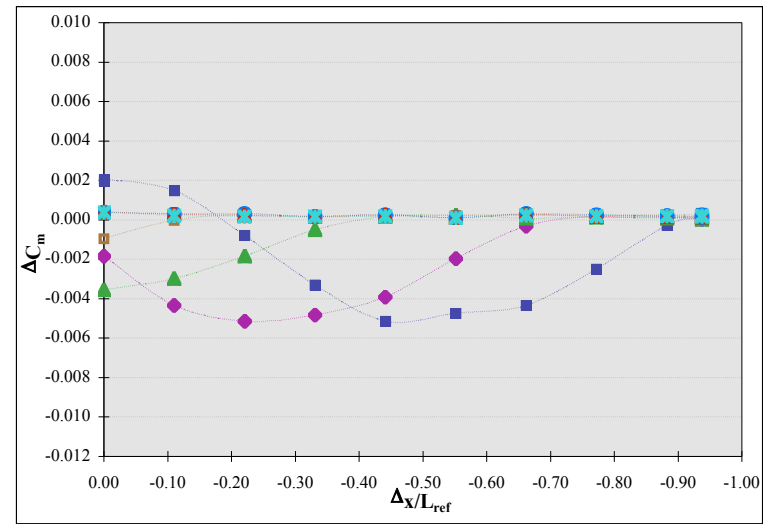

Vehicle 2 (Orbiter) @ 00 = 0 degrees

Figure 17. Proximity aerodynamic coefficients for Mach 6 at $\Pi=0$ and $\Pi \Pi=0$. 


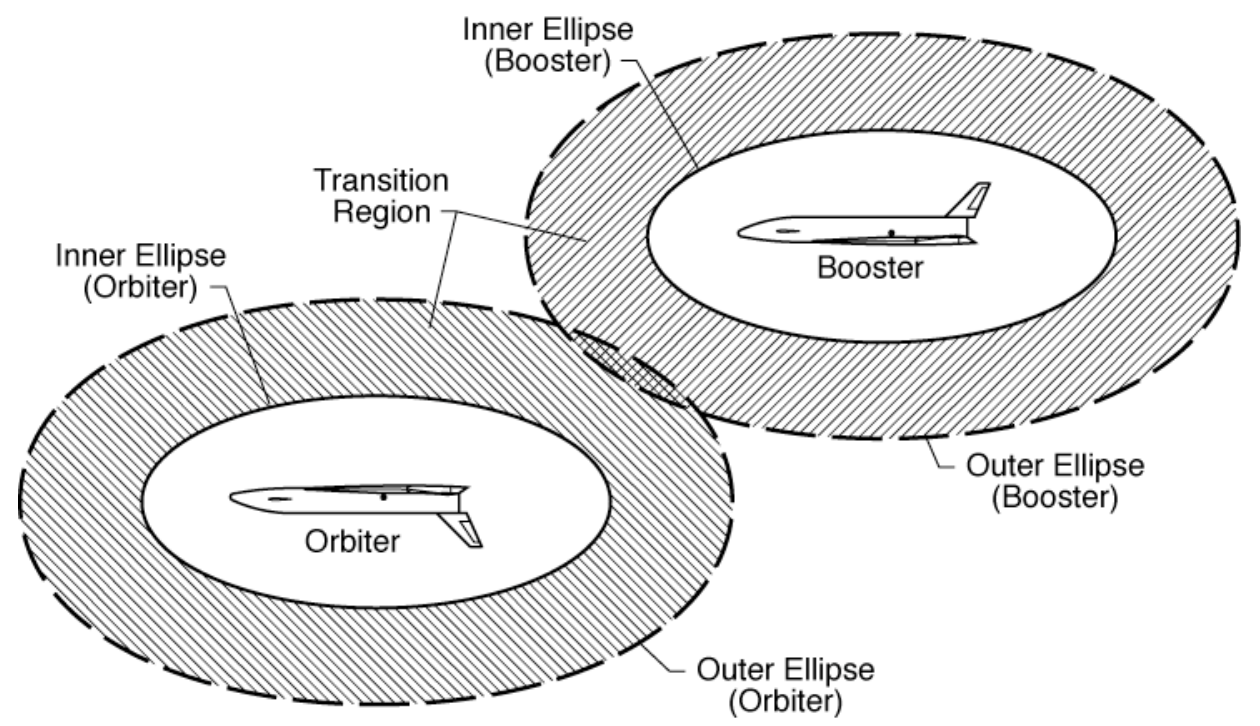

Figure 18. Schematic illustration of inner and outer ellipses and transition regions.
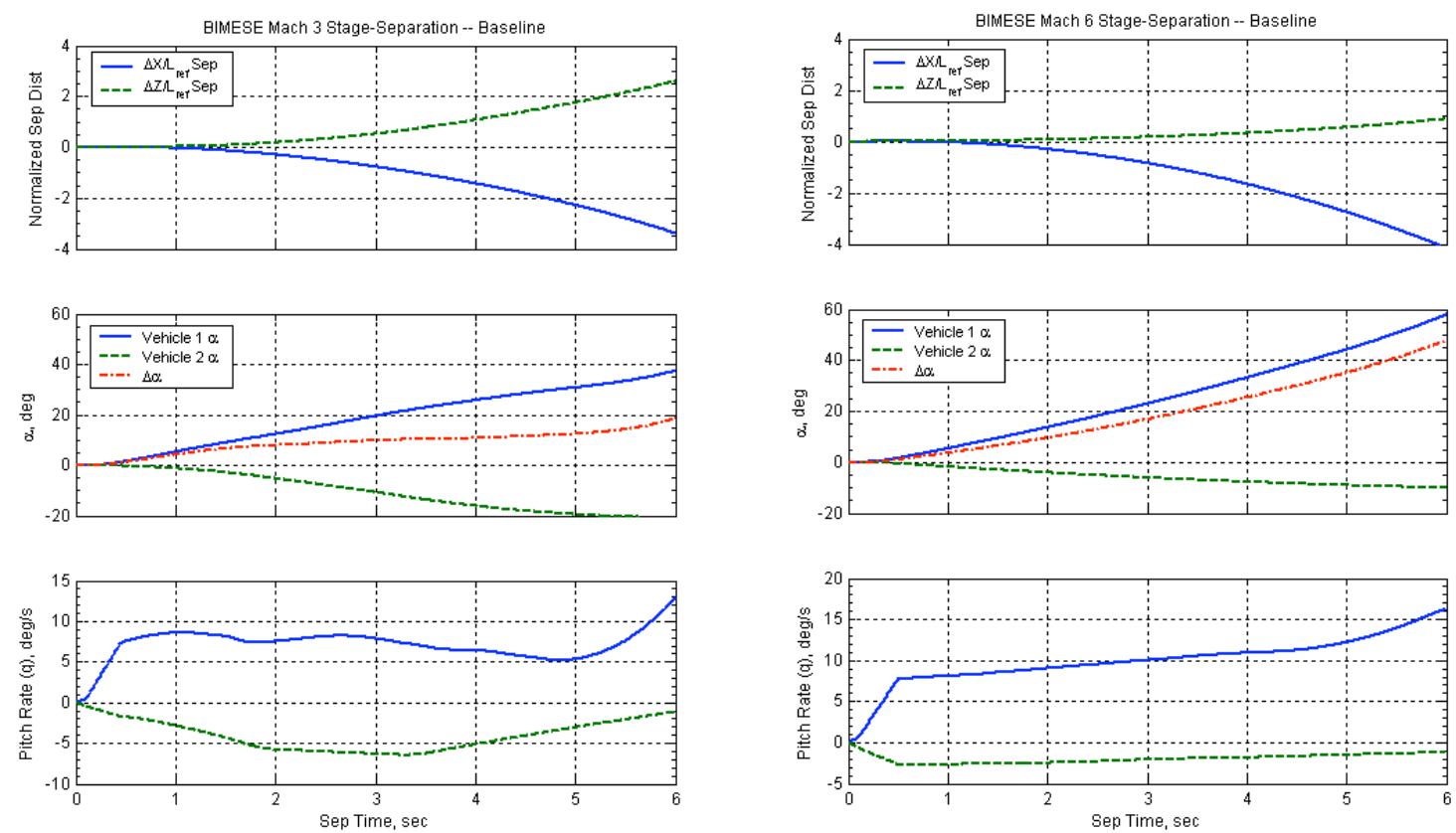

Figure 19. Mach 3 baseline separation.

Figure 20. Mach 6 baseline separation.

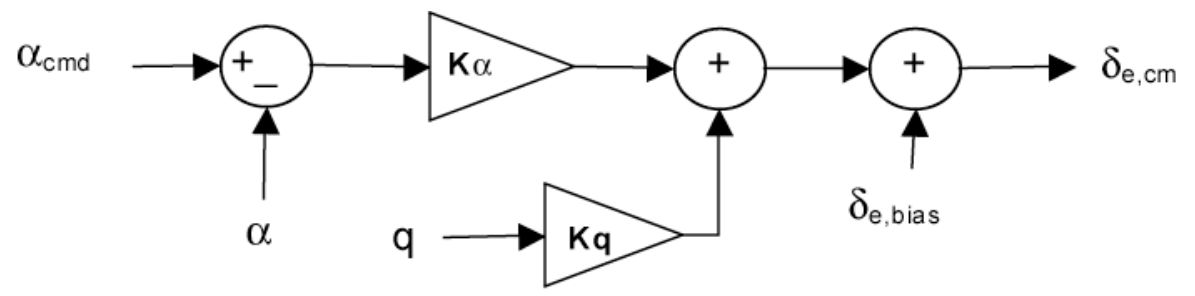

Figure 21. Feedback control system implemented in ConSep. 

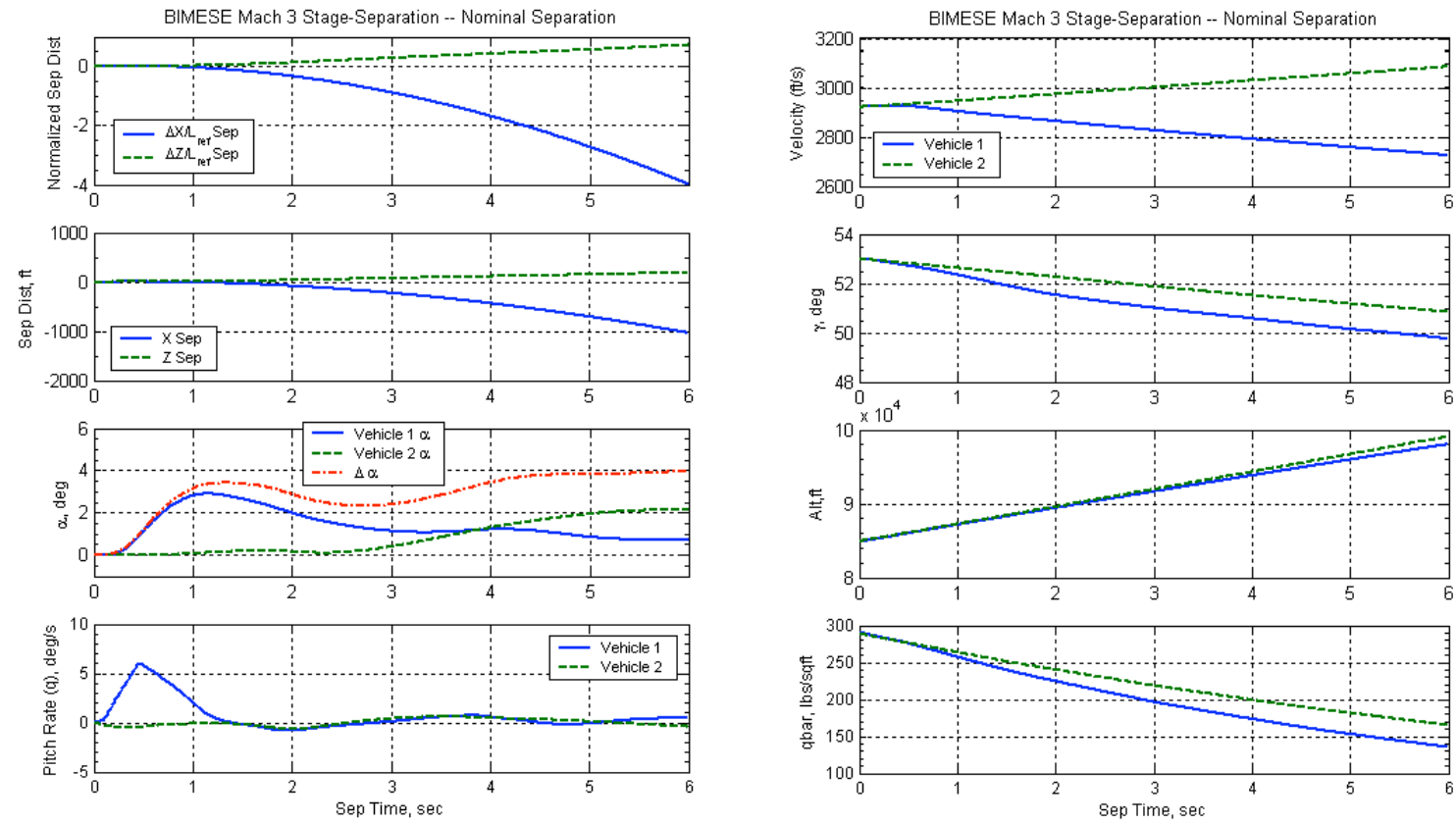

(a)

(b)
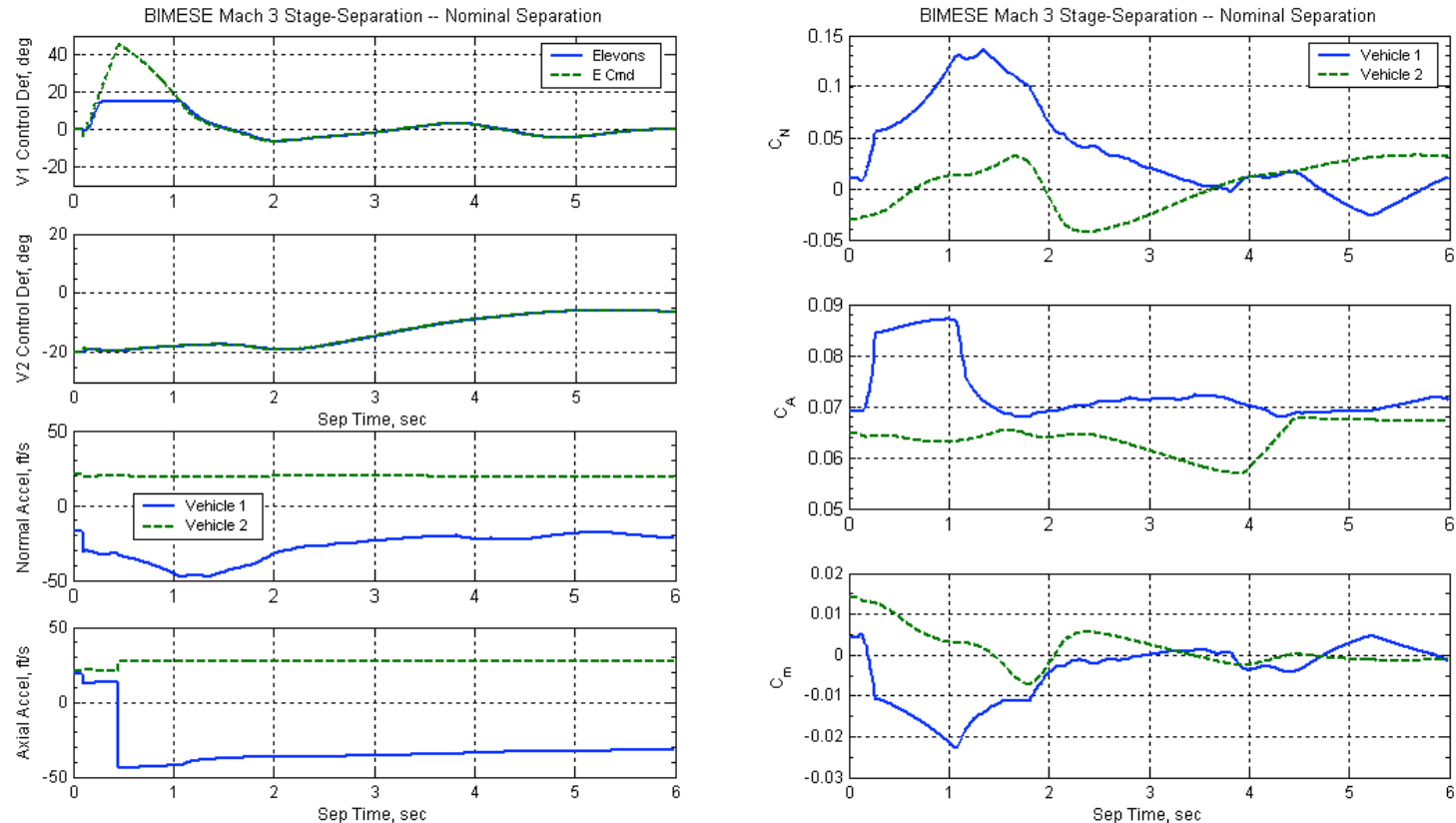

(c)

(d)

Figure 22. Nominal separation trajectory of Mach 3 staging LGBB-Bimese vehicle. 

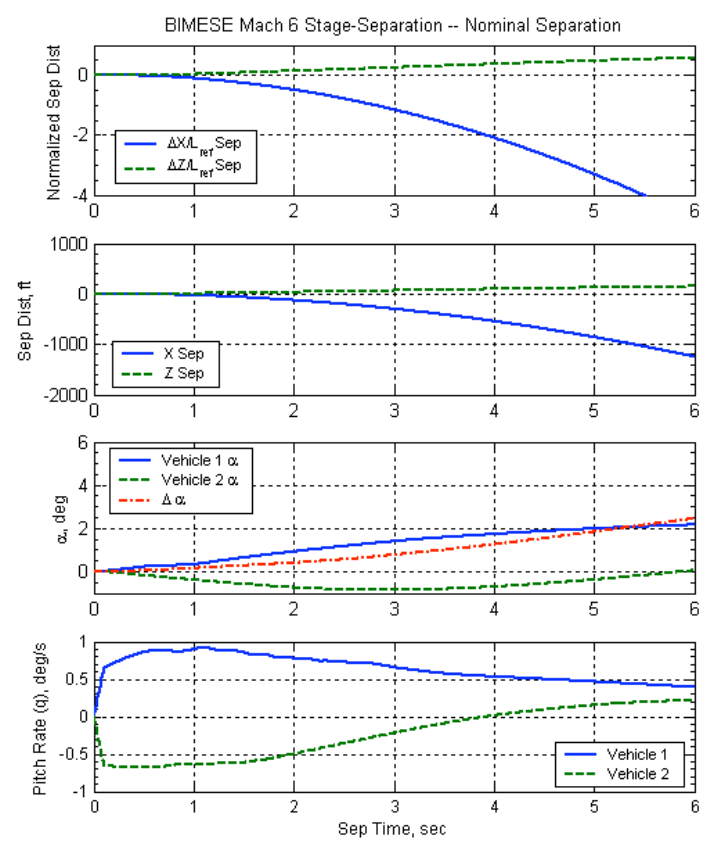

(a)
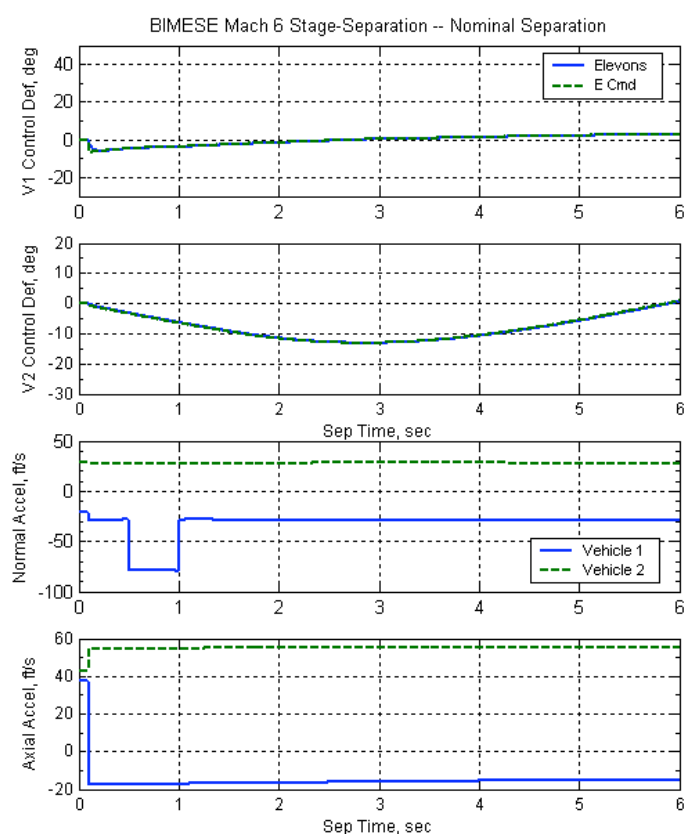

(c)
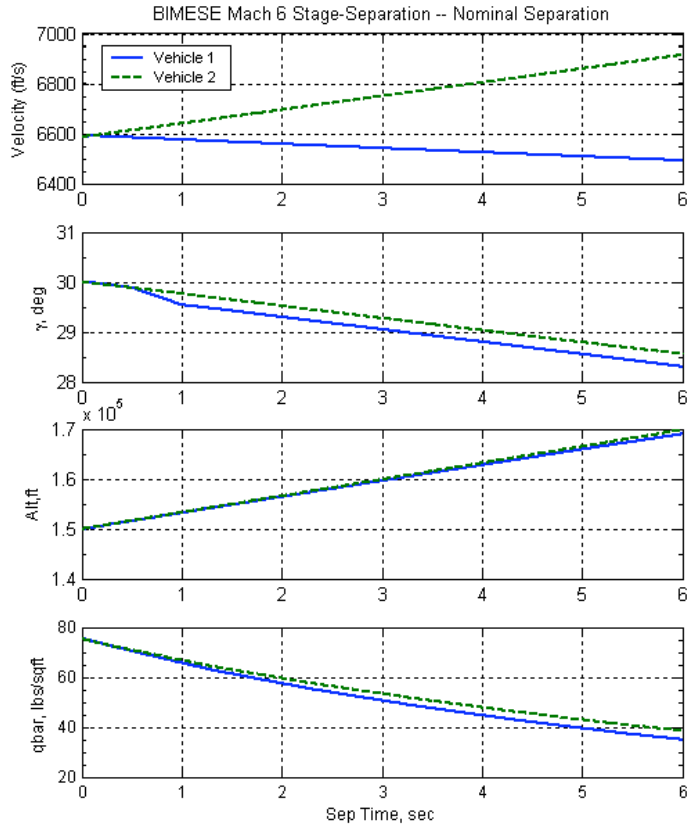

(b)
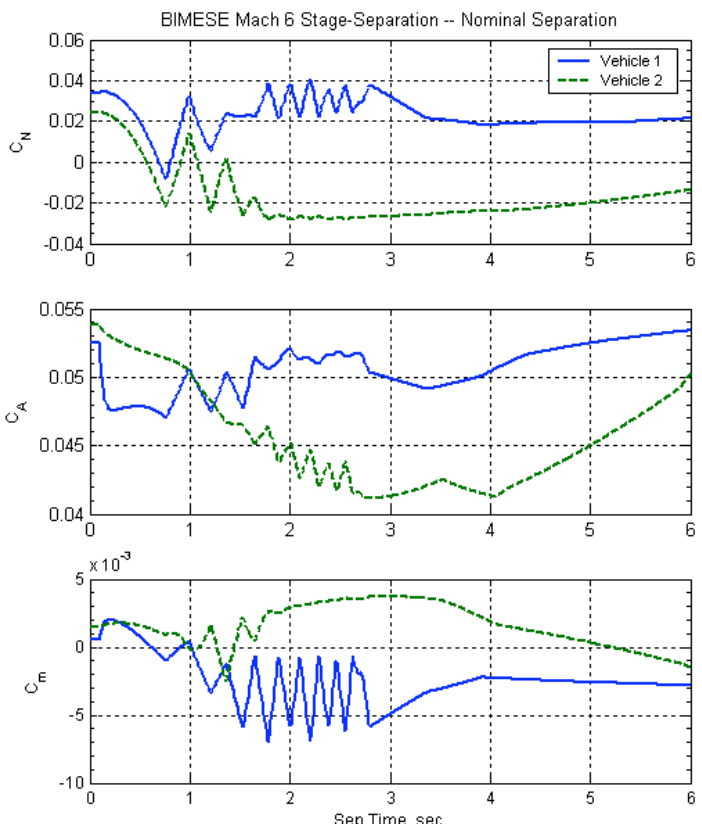

(d)

Figure 23. Nominal separation trajectory of Mach 6 staging LGBB-Bimese vehicle. 

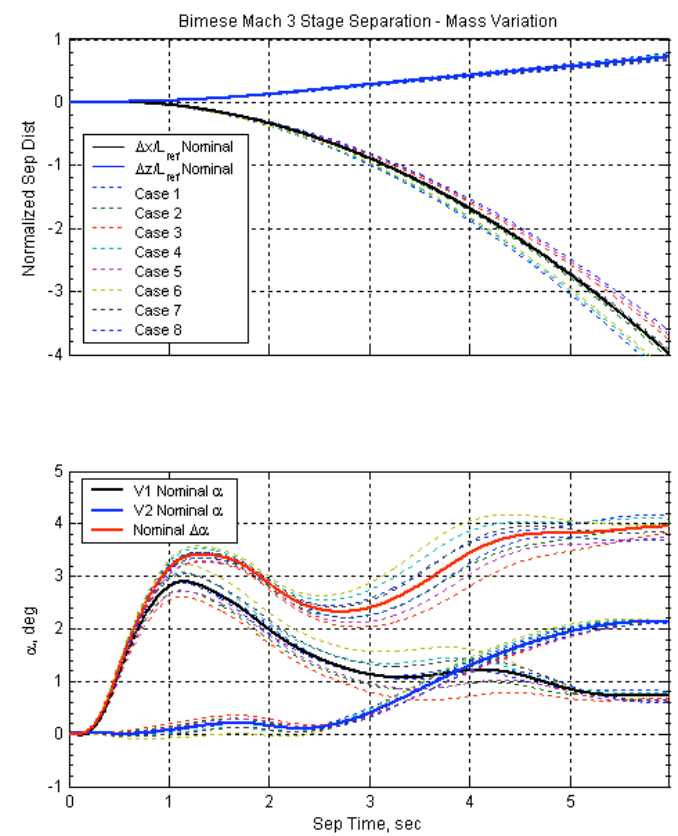

Figure 24. Effect of parametric variations in vehicle mass.
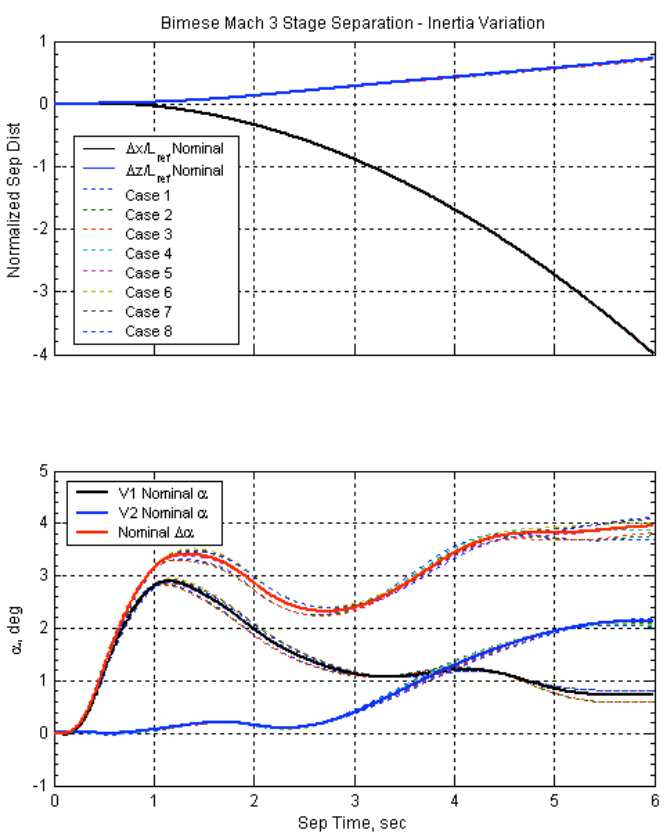

Figure 25. Effect parametric variation in inertia. 

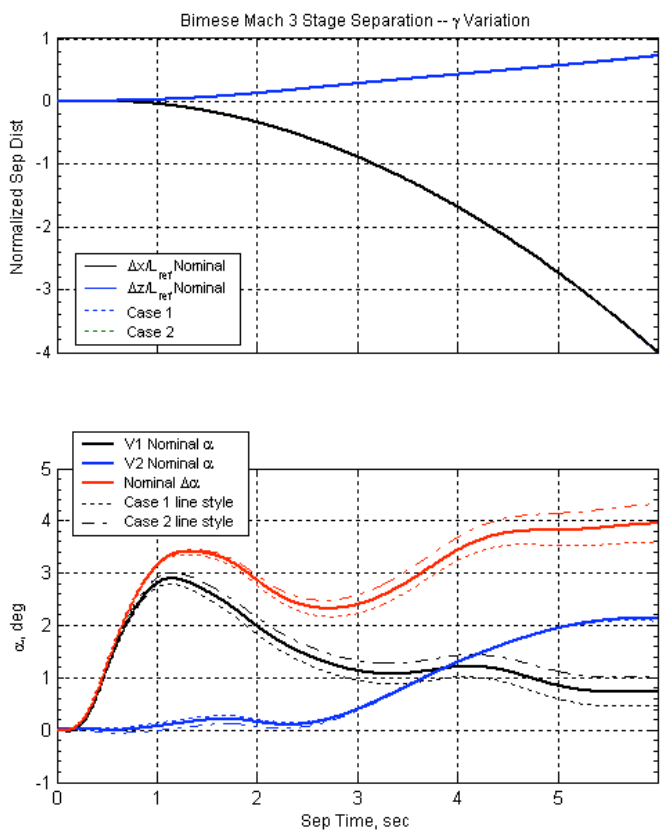

Figure 26. Effect of parametric variations in flight path angle.
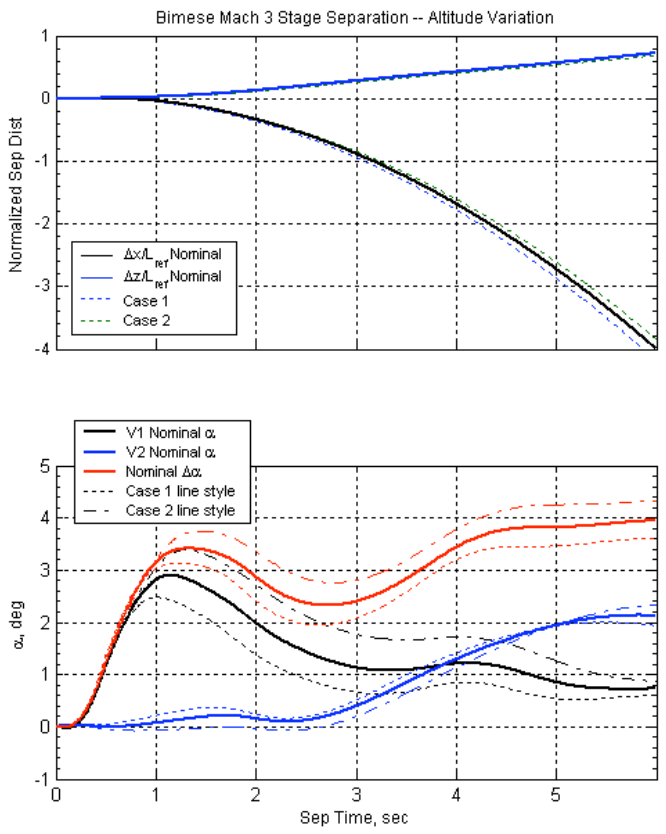

Figure 27. Effect of parametric variation in altitude. 

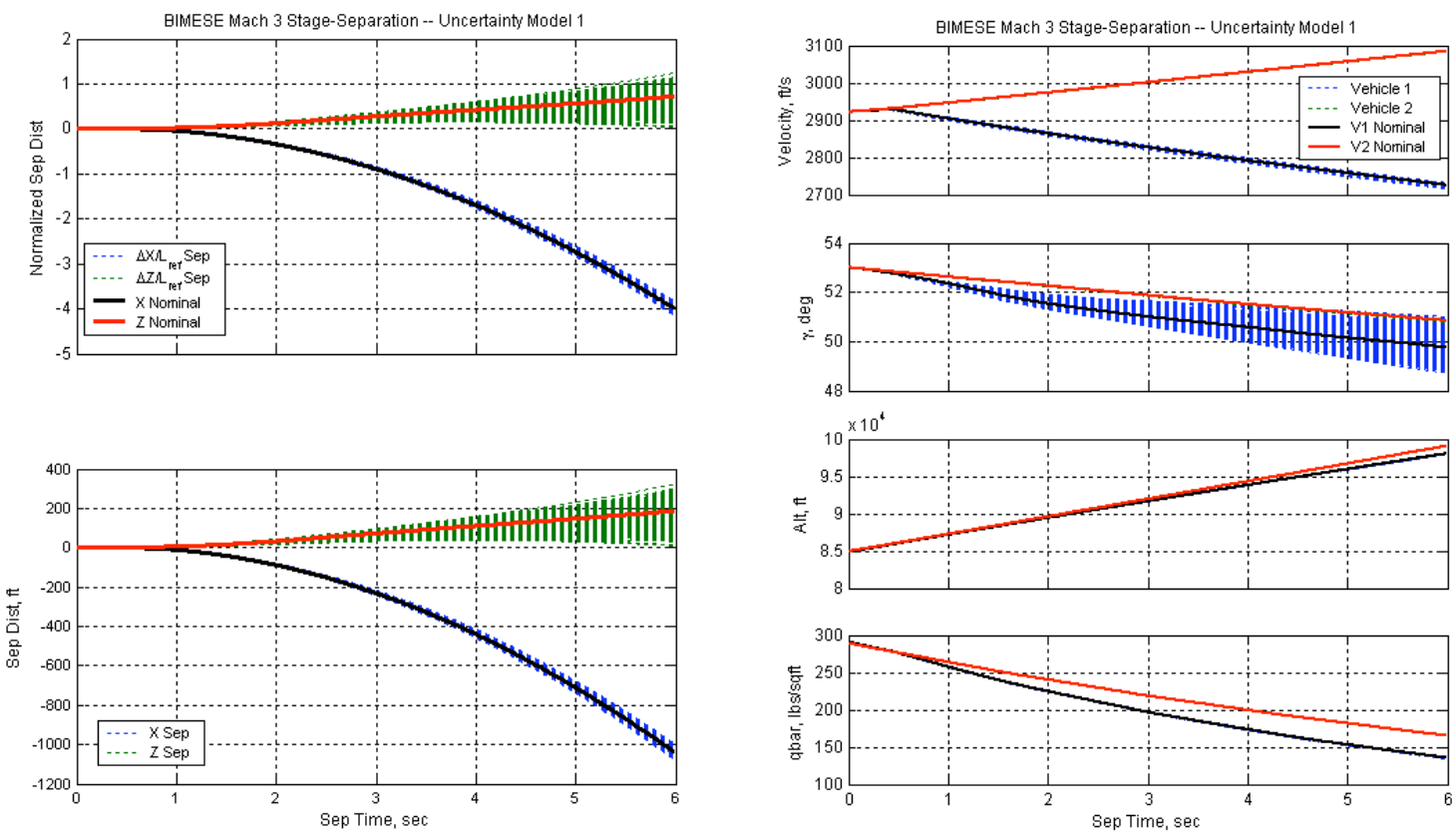

(a)

(b)
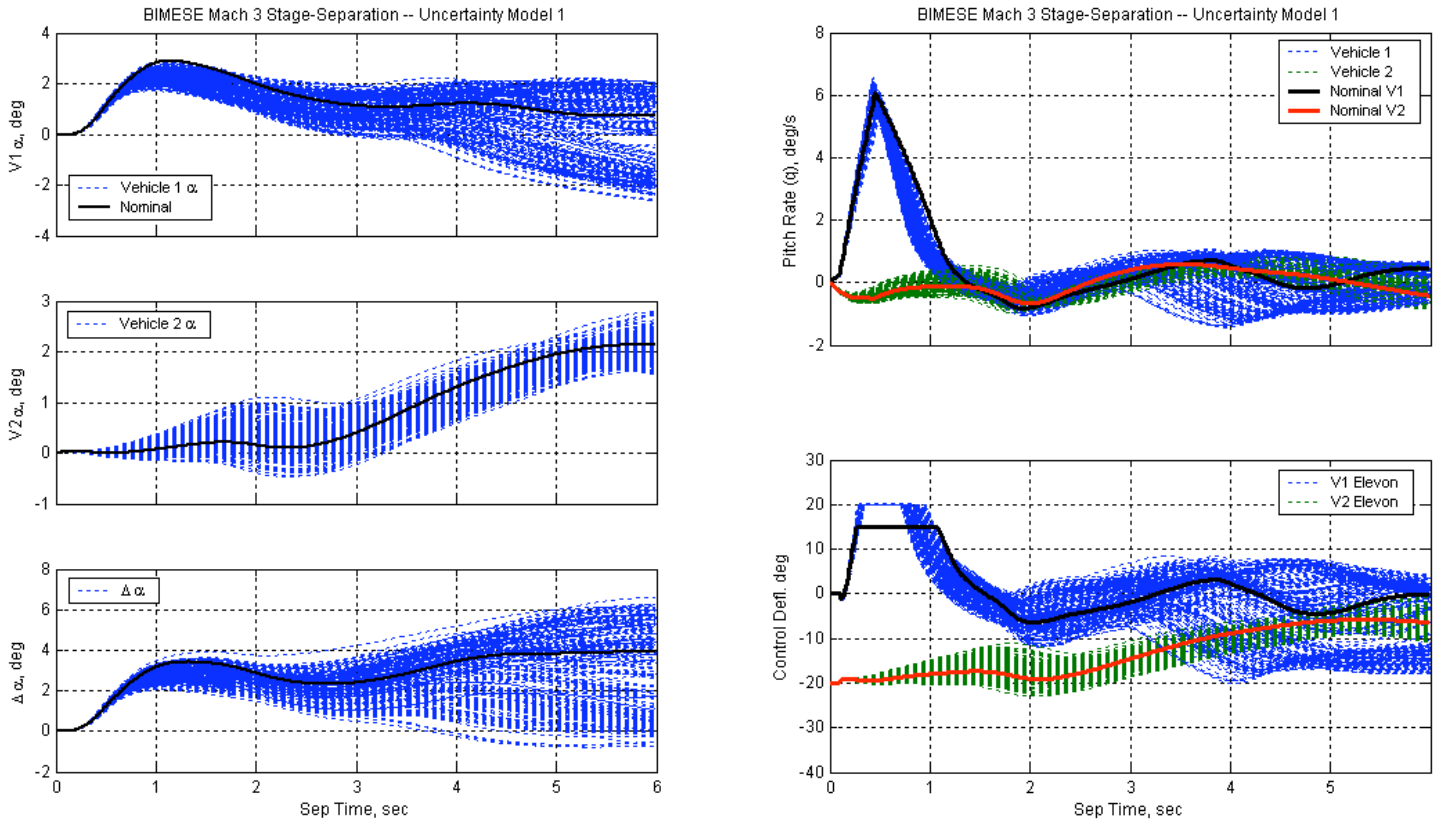

(c)

(d)

Figure 28. Monte Carlo trajectorires for the Mach 3 staging LGBB-Bimese vehicle. 


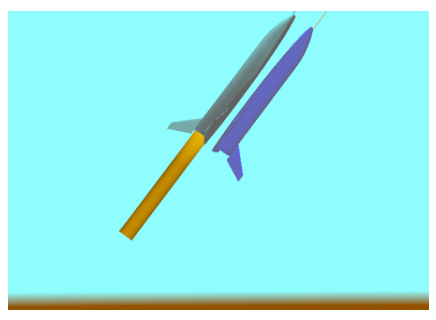

(a) $\mathbf{t}=\mathbf{0}$, Mated

Configuration.

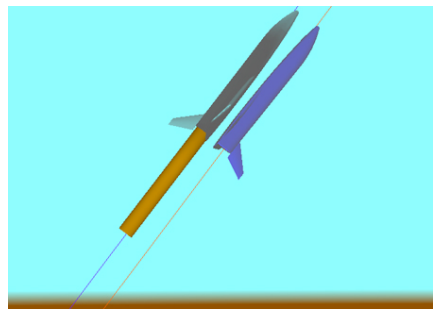

b) $\mathrm{t}=0.5 \mathrm{sec}, \mathrm{Aft}$ oint Release.

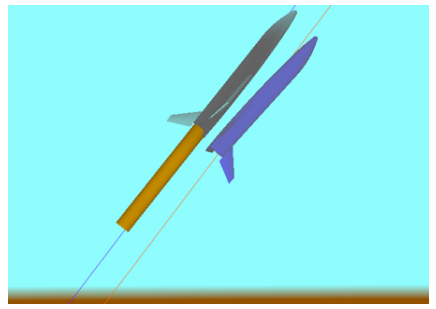

(c) $\mathbf{t}=1.0$ sec.

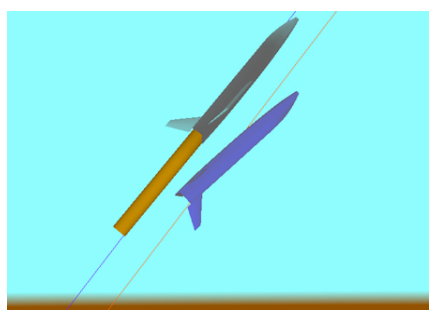

(d) $\mathbf{t}=\mathbf{2 . 0}$ sec.

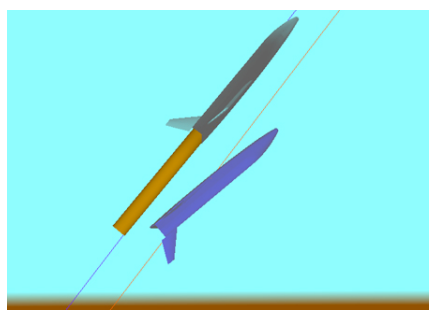

(e) $\mathrm{t}=2.5 \mathrm{sec}$.

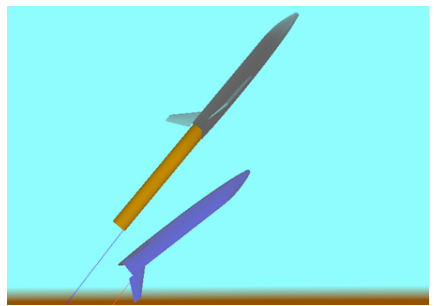

(f) $\mathbf{t}=3.0$ sec.

Figure 29. Relative location of vehicle during Mach 6 stage separation with gimbal angle control. 